\title{
Barriers and facilitators of pediatric shared decision-making: a systematic review
}

Laura Boland ${ }^{1,2}$, lan D. Graham ${ }^{2,3}$, France Légaré4, Krystina Lewis ${ }^{1}$, Janet Jull, ${ }^{5}$ Allyson Shephard ${ }^{6}$, Margaret L. Lawson ${ }^{6}$, Alexandra Davis ${ }^{7}$, Audrey Yameogo ${ }^{2}$ and Dawn Stacey ${ }^{1,2^{*}}$ (D)

\begin{abstract}
Background: Shared decision-making (SDM) is rarely implemented in pediatric practice. Pediatric health decisionmaking differs from that of adult practice. Yet, little is known about the factors that influence the implementation of pediatric shared decision-making (SDM). We synthesized pediatric SDM barriers and facilitators from the perspectives of healthcare providers (HCP), parents, children, and observers (i.e., persons who evaluated the SDM process, but were not directly involved).
\end{abstract}

Methods: We conducted a systematic review guided by the Ottawa Model of Research Use (OMRU). We searched MEDLINE, EMBASE, Cochrane Library, CINAHL, PubMed, and PsycINFO (inception to March 2017) and included studies that reported clinical pediatric SDM barriers and/or facilitators from the perspective of HCPs, parents, children, and/or observers. We considered all or no comparison groups and included all study designs reporting original data. Content analysis was used to synthesize barriers and facilitators and categorized them according to the OMRU levels (i.e., decision, innovation, adopters, relational, and environment) and participant types (i.e., HCP, parents, children, and observers). We used the Mixed Methods Appraisal Tool to appraise study quality.

Results: Of 20,008 identified citations, 79 were included. At each OMRU level, the most frequent barriers were features of the options (decision), poor quality information (innovation), parent/child emotional state (adopter), power relations (relational), and insufficient time (environment). The most frequent facilitators were low stake decisions (decision), good quality information (innovation), agreement with SDM (adopter), trust and respect (relational), and SDM tools/resources (environment). Across participant types, the most frequent barriers were insufficient time (HCPs), features of the options (parents), power imbalances (children), and HCP skill for SDM (observers). The most frequent facilitators were good quality information (HCP) and agreement with SDM (parents and children). There was no consistent facilitator category for observers. Overall, study quality was moderate with quantitative studies having the highest ratings and mixedmethod studies having the lowest ratings.

Conclusions: Numerous diverse and interrelated factors influence SDM use in pediatric clinical practice. Our findings can be used to identify potential pediatric SDM barriers and facilitators, guide context-specific barrier and facilitator assessments, and inform interventions for implementing SDM in pediatric practice.

Trial Registration: PROSPERO CRD42015020527

Keywords: Implementation, Pediatrics, Shared decision-making, Barriers, Facilitators, Systematic review, Taxonomy, Ottawa Model of Research Use

\footnotetext{
* Correspondence: dstacey@uottawa.ca

${ }^{1}$ Faculty of Health Sciences, University of Ottawa, 540 King Edward Avenue,

Ottawa, ON K1N 6N5, Canada

${ }^{2}$ Ottawa Hospital Research Institute, 501 Smyth Road, Ottawa, ON K1H 8L6,

Canada

Full list of author information is available at the end of the article
}

(c) The Author(s). 2019 Open Access This article is distributed under the terms of the Creative Commons Attribution 4.0 International License (http://creativecommons.org/licenses/by/4.0/), which permits unrestricted use, distribution, and reproduction in any medium, provided you give appropriate credit to the original author(s) and the source, provide a link to the Creative Commons license, and indicate if changes were made. The Creative Commons Public Domain Dedication waiver (http://creativecommons.org/publicdomain/zero/1.0/) applies to the data made available in this article, unless otherwise stated. 


\section{Introduction}

Shared decision-making (SDM) is an evidenced-based approach that promotes collaboration between patients, family members, and healthcare providers (HCP) when making health decisions. By exchanging information about the evidence (options, risks, and benefits) and the patient and family's preferences and values, HCPs, patients, and family members can deliberate to determine the best treatment plan [1]. This approach to decision-making is considered essential for patient-centered care, has garnered increasing international support among policy makers, and is recommended by pediatric regulatory organizations [2-4]. Nonetheless, implementation of SDM in pediatric healthcare remains limited $[5,6]$.

Determining the barriers and facilitators that influence the clinical use of evidence-based practices are critical for promoting their uptake [7]. Two systematic reviews have examined the barriers and facilitators of implementing SDM in adult medicine from the perspectives of HCPs and patients [8,9]. Findings showed that HCPs most commonly perceived time constraints, lack of applicability due to patient characteristics, and lack of applicability due to the clinical situation, as the main barriers [8]. Adult patients perceived power imbalances in the doctor-patient relationship and inadequate knowledge as primary barriers to SDM [9].

Several factors make health decision-making in pediatrics different from adult clinical practice. Children's evolving developmental context (e.g., biological, cognitive, and psychosocial variables) impacts their participation in health decisions. As such, determining the extent that children should be involved is difficult [10]. Pediatric decision-making is also complicated by the inclusion of multiple stakeholders (i.e., child, family members, and HCPs), each with their own preferences and values [11]. Parents or guardians act as surrogate decision makers. When faced with making difficult decisions on their child's behalf, parents or guardians must decide without knowledge of "what would the child do or want?". Further, the legislation and policy about pediatric health decisions can be complex, with different guiding principles depending on state/provincial laws, treatments being considered, and organizational policy [4]. Given this unique context, the barriers and facilitators that influence SDM in pediatrics likely differ from those identified in the adult literature.

Effective implementation of healthcare innovations requires knowledge about the barriers and facilitators influencing its use. When implementation interventions are designed to overcome identified barriers, there is an increased use of the innovation (e.g., SDM) in clinical practice [7]. Barriers and facilitators to knowledge use are also strong predictors of intention and behavior change [12]. In the adult literature, high-quality evidence underpins several implementation interventions, such as patient decision aids, decision coaching, and education and training, which facilitate SDM in clinical consultations [13-15]. Compared to the adult literature, few pediatric SDM implementation interventions have been developed, monitored, or evaluated $[16,17]$. A systematic review that evaluated the efficacy of SDM interventions in pediatrics found that of the 54 unique SDM interventions identified, 63\% targeted the parents. Only half of these interventions were evaluated. Meta-analysis suggested that SDM interventions might reduce parents' decisional conflict and improve their knowledge, but the impact on other adopters (e.g., children) was inconclusive [5]. Knowledge about the factors influencing SDM could inform and advance SDM implementation in pediatric practice. Therefore, we identified and synthesized the barriers and facilitators of SDM in pediatric practice from the perspectives of HCPs, parents, children, and observers (i.e., individuals who evaluated SDM, but did not participate in it).

\section{Methods \\ Design}

We conducted a systematic review, guided by the Cochrane Handbook for Systematic Reviews [18], and followed the PRISMA reporting guidelines [19]. Our protocol is registered in PROSPERO (ID: CRD42015020527) [20].

\section{Conceptual model}

We used the Ottawa Model of Research Use (OMRU) as our guiding theoretical model [21] (Fig. 1). The OMRU is a conceptual model of health research use derived from planned action theories, research utilization, and physician behavior change literature. The model seeks to explain the implementation of evidence into clinical practice using six key components: the innovation (evidence to be implemented), potential adopters, practice environment, implementation interventions, adoption, and outcomes. Given that these components are context-dependent, the OMRU outlines the following iterative process phases for implementing evidence: (1) assess barriers and facilitators related to the innovation, adopters, and practice environment; (2) design and implement interventions to minimize barriers and leverage facilitators; (3) monitor the use of evidence in clinical practice and the implementation process; and (4) evaluate outcomes and impact. Our review focuses on the first process phase of assessing barriers and facilitators.

A primary assumption underpinning the OMRU is that barrier and facilitator assessments are essential for informing the selection of implementation strategies. During the iterative coding and content analysis phase, we added two additional levels to reflect our data: the 


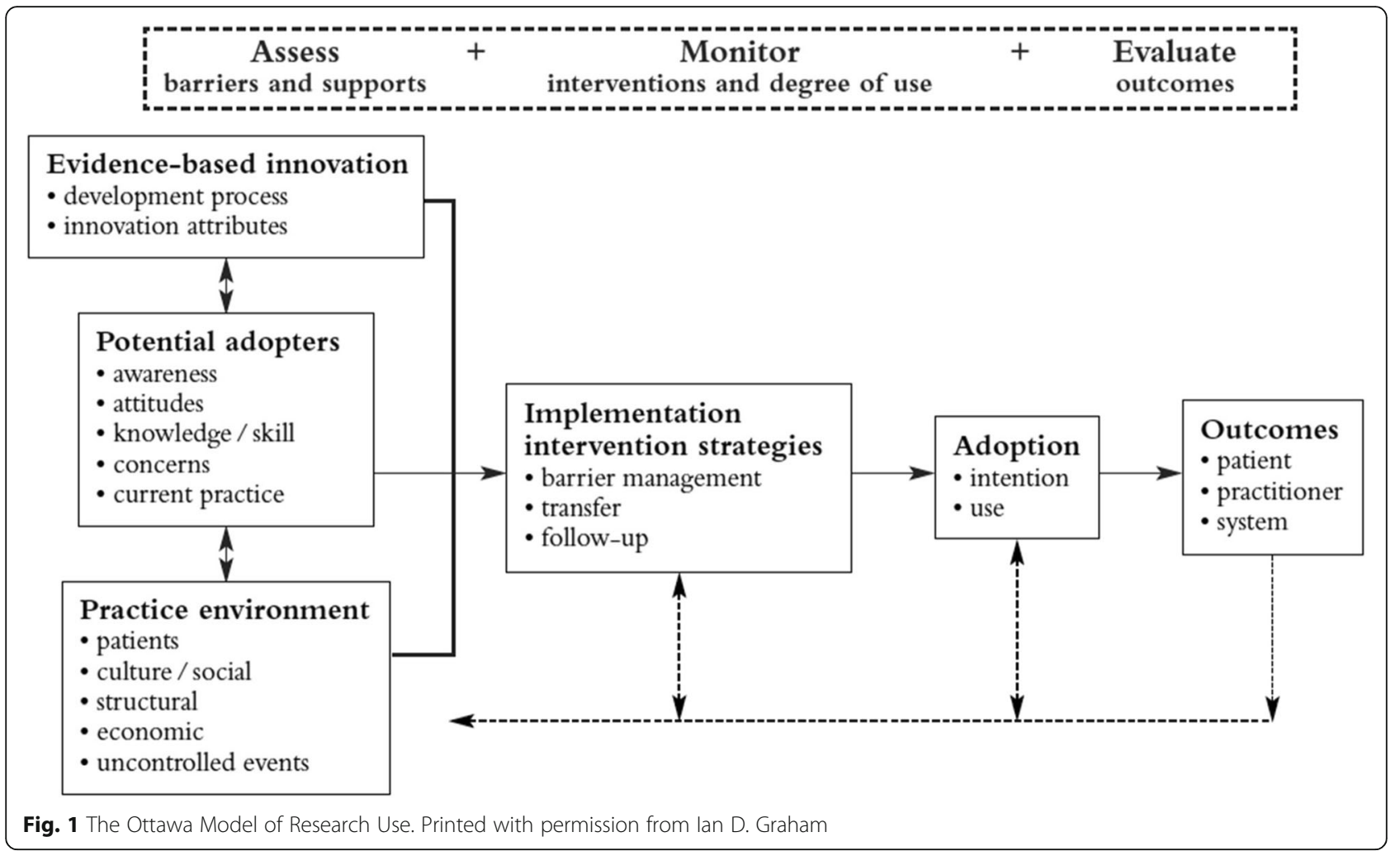

decision level and the relational level $[9,22]$. We defined each OMRU level as follows: (A) the decision level includes influencing factors related to the decision itself or that are antecedent to the SDM process (e.g., features of the options and high or low stake decisions); (B) the innovation was SDM or a collaborative decision-making approach between HCPs, parents, and/or children; (C) adopters are the individuals who use the innovation, in this case, HCPs, parents, and children; (D) relational represents the interpersonal interactions and processes between the $\mathrm{HCP}$, patient, and family during the SDM discussions [22]; and, (E) the practice environment, in this case the pediatric clinical setting, which includes structural factors (e.g., legislation, policy, physical structures, and workload).

\section{Inclusion criteria}

We used the PICOS framework to guide our eligibility criteria [23] (Table 1). Eligible participants included HCPs (e.g., frontline staff of any discipline, clinical managers,

Table 1 Study eligibility criteria

\begin{tabular}{|c|c|c|}
\hline & Included & Excluded \\
\hline Participants & $\begin{array}{l}\text { Healthcare providers } \\
\text { Parents, guardians, and/or caregivers } \\
\text { Children } 18 \text { years of age or younger } \\
\text { Observers }\end{array}$ & $\begin{array}{l}\text { Adult patients (19 years and older) and } \\
\text { individuals involved in making a decision about } \\
\text { the health of an adult patient }\end{array}$ \\
\hline Intervention & $\begin{array}{l}\text { SDM in the pediatric clinical context } \\
\text { A collaborative decision-making } \\
\text { approach consistent with SDM }\end{array}$ & $\begin{array}{l}\text { Non-SDM interventions } \\
\text { Hypothetical decisions } \\
\text { Health decisions in a non-clinical setting (e.g., schools) } \\
\text { Decisions about pregnancy, perinatal care (before birth) } \\
\text { Decisions about participation in research }\end{array}$ \\
\hline Comparison & All comparison groups, including none & \\
\hline Outcomes & $\begin{array}{l}\text { Barriers and/or facilitators of SDM in } \\
\text { pediatric clinical and/or health care practice } \\
\text { Note: outcomes had to be reported in } \\
\text { the results section of the paper }\end{array}$ & $\begin{array}{l}\text { All other SDM outcomes (e.g., impact of a } \\
\text { SDM intervention) }\end{array}$ \\
\hline Study methods & All study designs with original data & $\begin{array}{l}\text { Reviews } \\
\text { Commentaries } \\
\text { Unpublished studies }\end{array}$ \\
\hline
\end{tabular}


and administrators), parents or guardians (collectively referred to as parents), children aged 18 years or less, and observers. Observers are individuals who were not involved in the pediatric SDM process, but evaluated SDM in some way (e.g., research assistants who evaluated SDM in person or in videotaped consultations using a validated instrument). Observers differ from adopters, in that adopters are involved in the SDM process. We collectively refer to HCPs, parents, children, and observers as "participants." The intervention was SDM or a collaborative decision-making approach regarding a decision about a child's health $[1,10]$. Outcomes were barriers or facilitators of SDM in pediatric clinical practice reported in the results section of the included study. We excluded studies that reported on barriers and facilitators of health decisions for combined pediatric and adult patient populations (e.g., family practice primary care). We included all study designs with original data, with or without comparison groups. There were no language restrictions. These parameters are consistent with previous systematic reviews that examined SDM barriers and facilitators in adult clinical practice $[8,24]$.

\section{Information sources and search strategy}

An information specialist (AD) designed the search strategy and conducted electronic searches specific to each database with input from our research team. The search was designed to target SDM barriers and facilitators in pediatric clinical practice (see Additional file 1). We searched the following electronic databases (from inception to March 2017): MEDLINE, EMBASE, Cochrane Library, PubMed, PsycINFO, and CINAHL. Review of reference lists of included studies did not identify additional studies.

\section{Study selection}

We uploaded citations onto a title and abstract screening web application, designed by an information technologist (AS) at our research institute. This application allowed reviewers (LB, KL, JJ, DS, AS) to independently evaluate study eligibility in a three-stage screening process. First, titles were randomly assigned to two independent reviewers and screened to determine their relevance to decision-making in pediatrics. Reviewers did not know if they were screening first or second and indicated whether an article was "included," "excluded," or "unsure" based on the eligibility criteria. Both reviewers were required to determine that an article was excluded for it to be screened out, while titles deemed "included" or "unsure" by at least one reviewer moved to the second screening stage. We followed the same process for abstracts. Finally, two reviewers independently read full texts to determine eligibility. At this stage, reviewers reached consensus for study inclusion and exclusion.

\section{Data collection}

Two reviewers independently extracted data using a standardized and pre-piloted data extraction form. We extracted citation information (e.g., country of origin, language), study information (e.g., objectives, design, and methodological approaches), participant types (i.e., HCP, parent, child, and observer), and findings (i.e., barriers and facilitators). Inconsistencies in extracted data were resolved through consensus, as outlined by the Cochrane Handbook for Systematic Reviews [18].

\section{Analysis}

Pooling of quantitative data was inappropriate due to the heterogeneity across included studies regarding design, decision type and timing, adopters involved, methods, and measures used. We synthesized the barriers and facilitators using deductive and inductive content analysis. This involved becoming familiar with the data, identifying units of relevant data, open-coding, category development, compiling data, and iterative data comparison between coders $[25,26]$. We transferred the extracted text representing the barriers and facilitators into NVivo qualitative analysis software (NVivo; QSR International Pty Ltd. V10, 2012). Two coders conducted the analysis, which was informed by taxonomies derived from systematic reviews of SDM barriers and facilitators in adult clinical practice, from the perspectives of healthcare providers and patients $[8$, 9]. These taxonomies describe a range of factors that influence the implementation of SDM in adult clinical practice. Categories were organized under the OMRU levels (i.e., decision, innovation, adopter, relational, and environmental). An advantage of using the OMRU to categorize findings is that interventions can be selected to target the barriers at the level in which the barrier is occurring. Then, we rank-ordered the influential factor according to the frequency of studies that reported it. We counted the barrier and facilitator frequency once per study. Specifically, if one paper reported the same barrier or facilitator multiple times, we counted it once. However, if the same factor was reported as both a barrier and facilitator, we counted it once for each a barrier and facilitator. When a study reported multiple perspectives (e.g., HCPs and parents), and each participant type reported the same barrier or facilitator, we counted the factor once (as defined above) for each participant type.

In summary, our analysis used a complementary approach to promote a theory-driven and evidence-based deduction, induction and categorization of pediatric SDM barriers and facilitators. First, we drew from systematic reviews on SDM barriers and facilitators in adult practice to ensure a comprehensive assessment of SDM barriers and facilitators within our included 
studies. Second, we used the OMRU to categorize these findings in a manner conducive to informing future pediatric SDM implementation efforts.

\section{Quality assessment}

Two independent raters appraised study quality using the Mixed Method Appraisal Tool (MMAT) [27, 28]. The MMAT criteria (Table 3) were developed based on a thematic analysis of the quality appraisal processes revealed by health-related systematic reviews. The tool was designed to concurrently appraise qualitative, quantitative, and mixed method studies for large and complex systematic reviews [27]. The MMAT reliability is reported to range from fair to perfect [28] and is well suited for the assessment of complex interventions that are context-dependent and process-oriented, such as SDM. We report items scores at the individual study level (Table 3) and overall (see the "Study appraisal" section). Raters resolved discrepancies through discussion and consensus.

\section{Results}

Identified studies and characteristics

Our search yielded 20,008 citations (Fig. 2). After removing duplicates and screening titles and abstracts, we examined 461 full-text articles, of which 79 publications (representing 78 distinct studies) were included. Included studies were published between 1996 and 2017, with increasing publications over time (Fig. 3).

All studies were published in English except one, which was French [29]. Studies originated from 15 countries: the USA $(n=34)$, the UK $(n=13)$, Canada $(n=9)$, Ireland $(n=5)$, Sweden $(n=3)$, Australia $(n=$ $3)$, the Netherlands $(n=2)$, one study from each of France, Italy, Israel, Kenya, South Africa, Switzerland, Amsterdam, Turkey, and both Canada and the USA together (Table 2).

Barriers and facilitators were reported from the perspective of HCPs $(n=19)$, parents $(n=18)$, children $(n=8)$, multiple perspectives $(n=26)$, and observers $(n=7)$. Data from 47,363 participants were synthesized, including

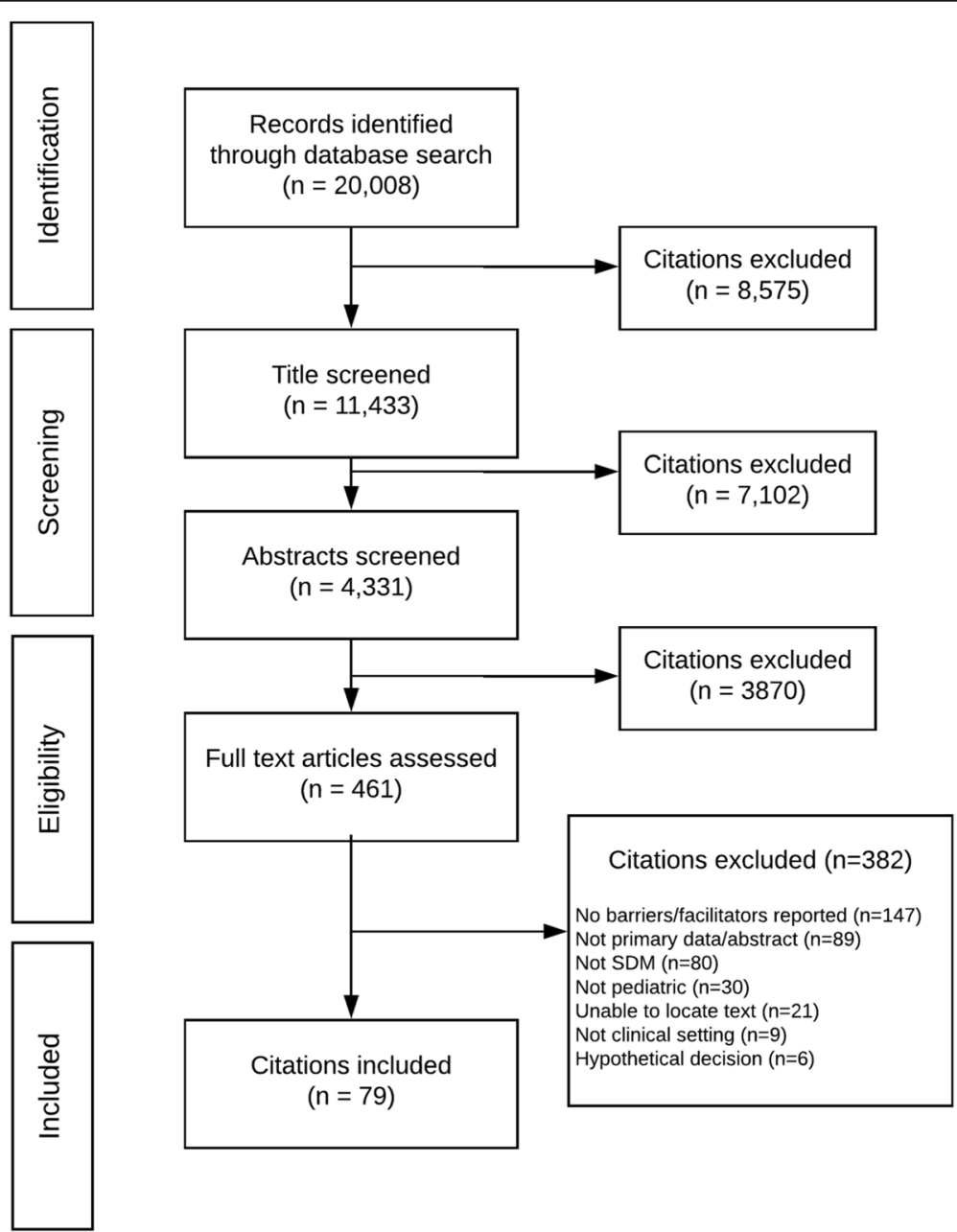

Fig. 2 Literature flow chart 


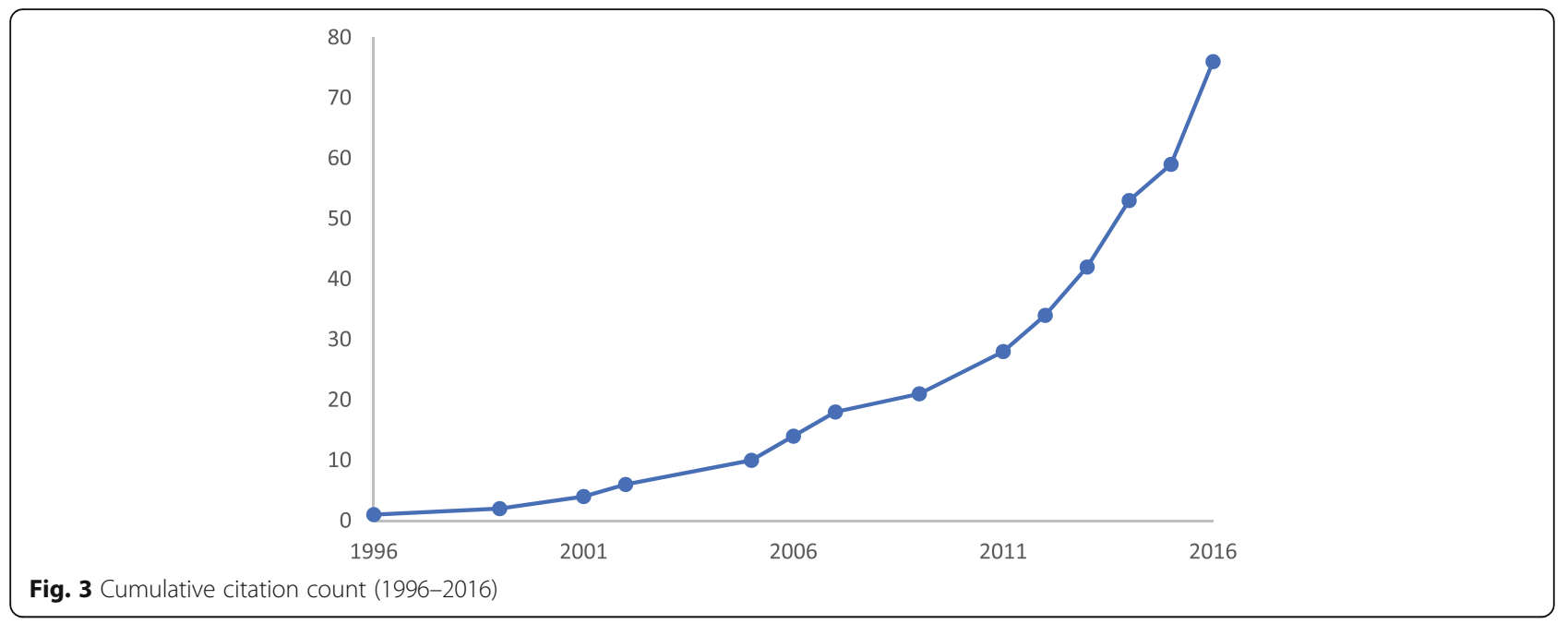

45,094 parents (95\%), $1785 \mathrm{HCPs}(4 \%)$, and 484 children (1\%). We also included data from more than 138 observed consultations $(n=6)$ plus 135 observed consultation hours $(n=1)$. Observer studies primarily reported on the HCP's behavior.

\section{Study appraisal}

The MMAT appraisal results are shown in Table 3. Included studies used qualitative $(n=47 ; 60 \%)$, quantitative ( $n=18 ; 23 \%$ ), and mixed methods $(n=14 ; 18 \%)$. For qualitative studies, $100 \%$ of studies reported sources of data relevant to address the research question. Sources of bias included not reporting how: findings related to researchers' influence ( $n=39 / 47,83 \%$ missed), findings related to context ( $n=12 / 47,26 \% \mathrm{missed} /$ unsure), and the process for analysis was relevant to address the research question ( $n=4 / 47,9 \%$ missed/unsure).

For quantitative studies, all studies received credit for having a sampling strategy relevant to the research question. Sources of bias included not reporting if the sample was representative $(n=5 / 18,28 \%$ missed/unsure), if the measures used were appropriate (i.e., of known origin, valid, or standardized) $(n=4 / 18 ; 22 \%$ missed/unsure), and whether the response rate was $60 \%$ or above ( $n=4 / 18,22 \% \mathrm{missed} /$ unsure) .

The mixed method studies had the lowest ratings. All studies received credit for having relevant sources of data appropriate for the research question and a research design that was relevant to address a qualitative and quantitative research question. Other sources of bias were how findings related to researchers' influence $(n=14 / 14,100 \%$ missed), how limitations associated with integration of qualitative and quantitative approaches $(n=13 / 14,93 \%$ missed), how findings related to the context $(n=9 / 14$, $64 \%$ missed), if the sample was representative of the population under study ( $n=6 / 14,42 \%$ missed), if measurements used were appropriate ( $n=5 / 14,36 \%$ missed), if an acceptable response rate was reported $(n=5 / 14,36 \%$ missed), integration of qualitative and quantitative data relevant to address the research question(s) $(n=3 / 14,21 \%$ missed), if the data analysis was relevant to the research question ( $n=1 / 14,7 \%$ unsure), and if the sampling strategy was relevant to address the research question $(n=1$ / $14,7 \%$ unsure).

\section{Pediatric SDM barriers and facilitators}

We report our findings in several formats, including a narrative report of frequently cited barriers and facilitators under each OMRU level (below), a detailed taxonomy of pediatric SDM barriers and facilitators, including frequency counts across OMRU levels and participant types (Table 4), and influential factors (not separated into barriers and facilitators) mapped to the OMRU (Fig. 3).

\section{Decision level ( $n=19$ studies)}

Barriers Features of the options was the most frequently cited barrier category at the level of the decision (Table 4), was reported by all adopters, and was the main barrier reported by parents. Features included a perceived lack of options, unacceptable alternatives, and affordability. Adopters, particularly parents, also reported that lack of research evidence for the various options was a barrier to engaging in the SDM process.

Facilitators The perceived magnitude of the decision being discussed influenced the extent to which SDM was encouraged and preferred. Overall, lower stake decisions were reported by all adopters to facilitate SDM in pediatrics. Specifically, HCPs and parents reported being more willing to involve children in decisions when the potential outcomes were considered less risky. Similarly, children reportedly preferred to be involved in lower stake decisions. 


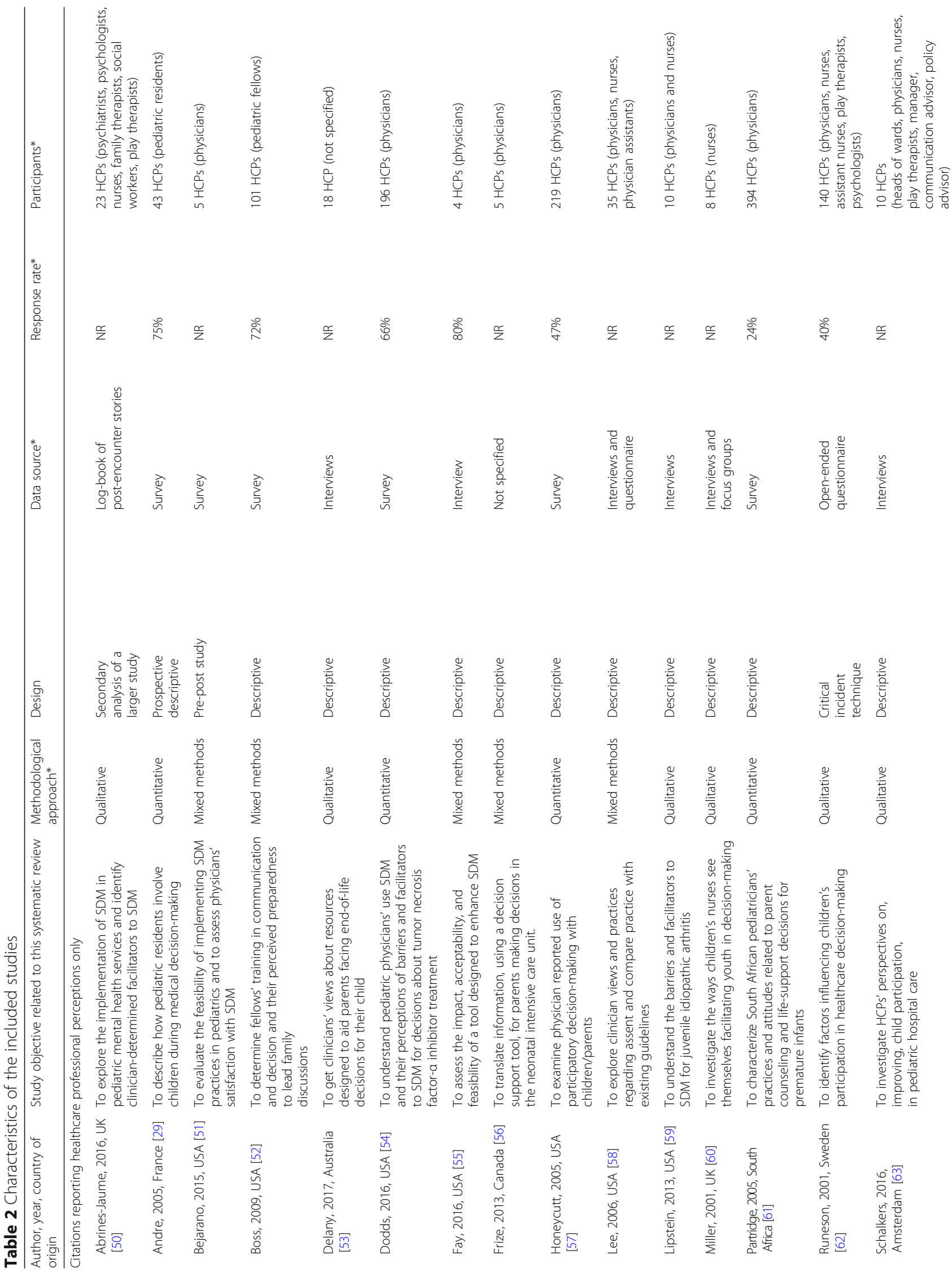




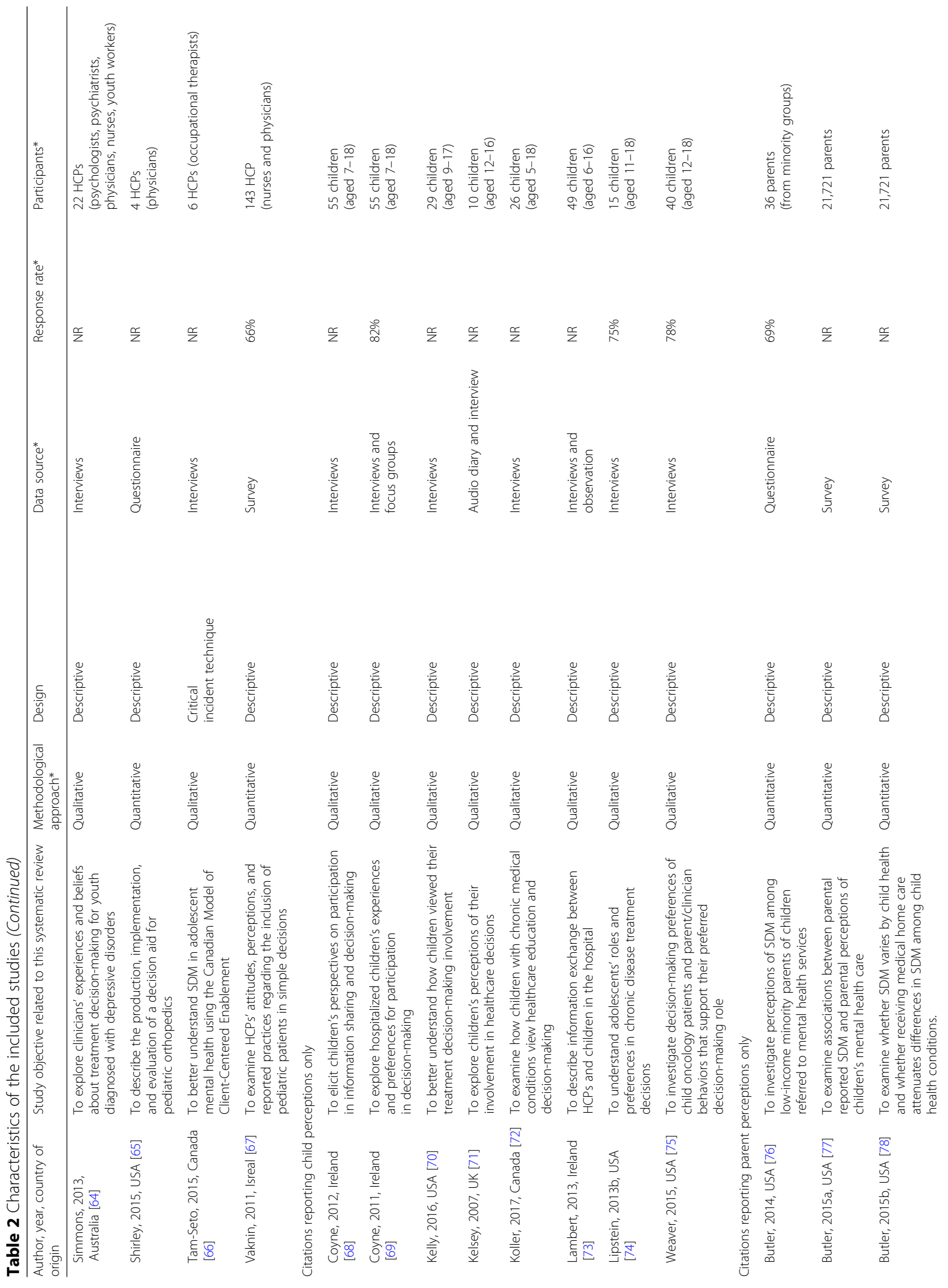




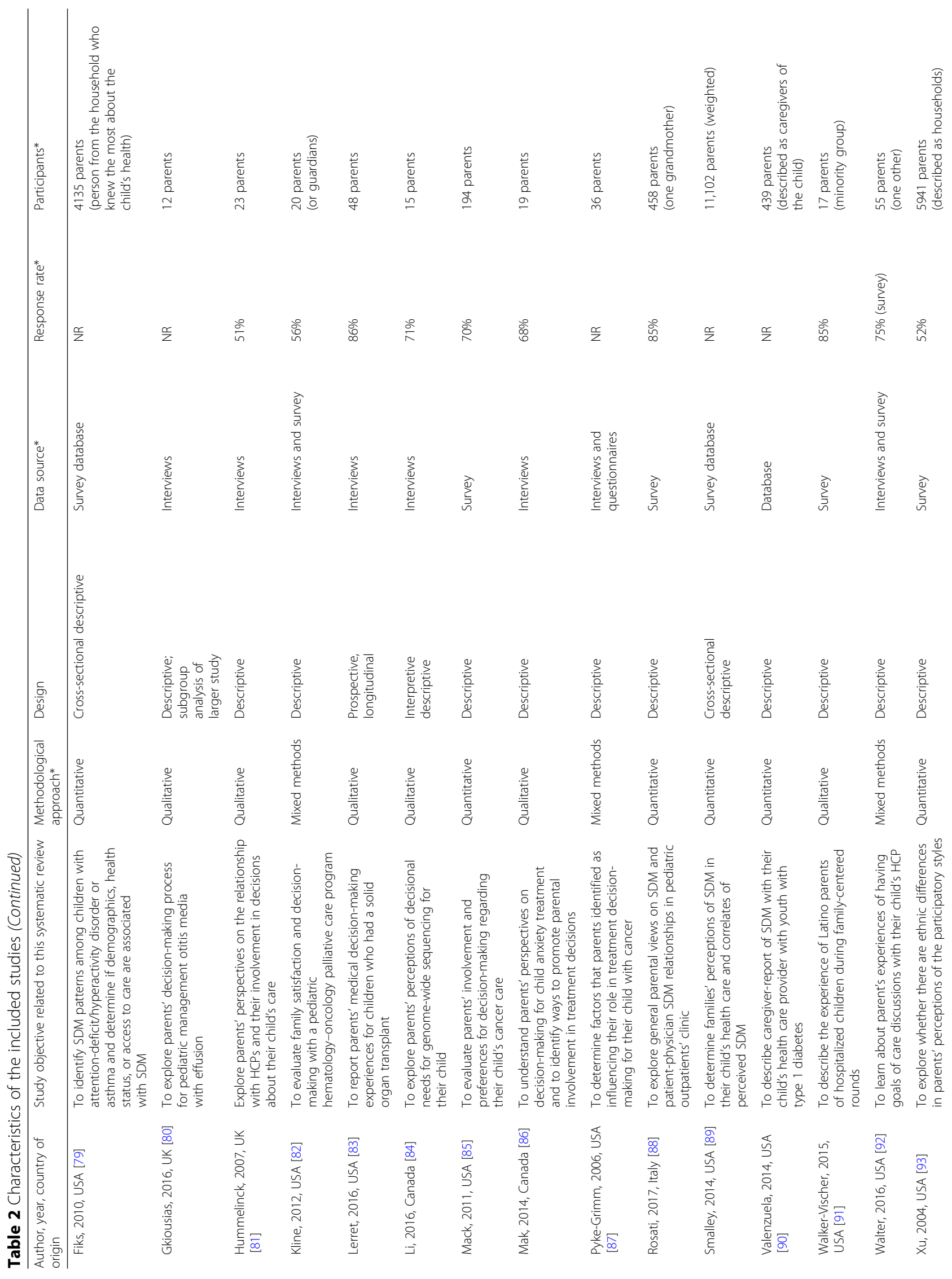




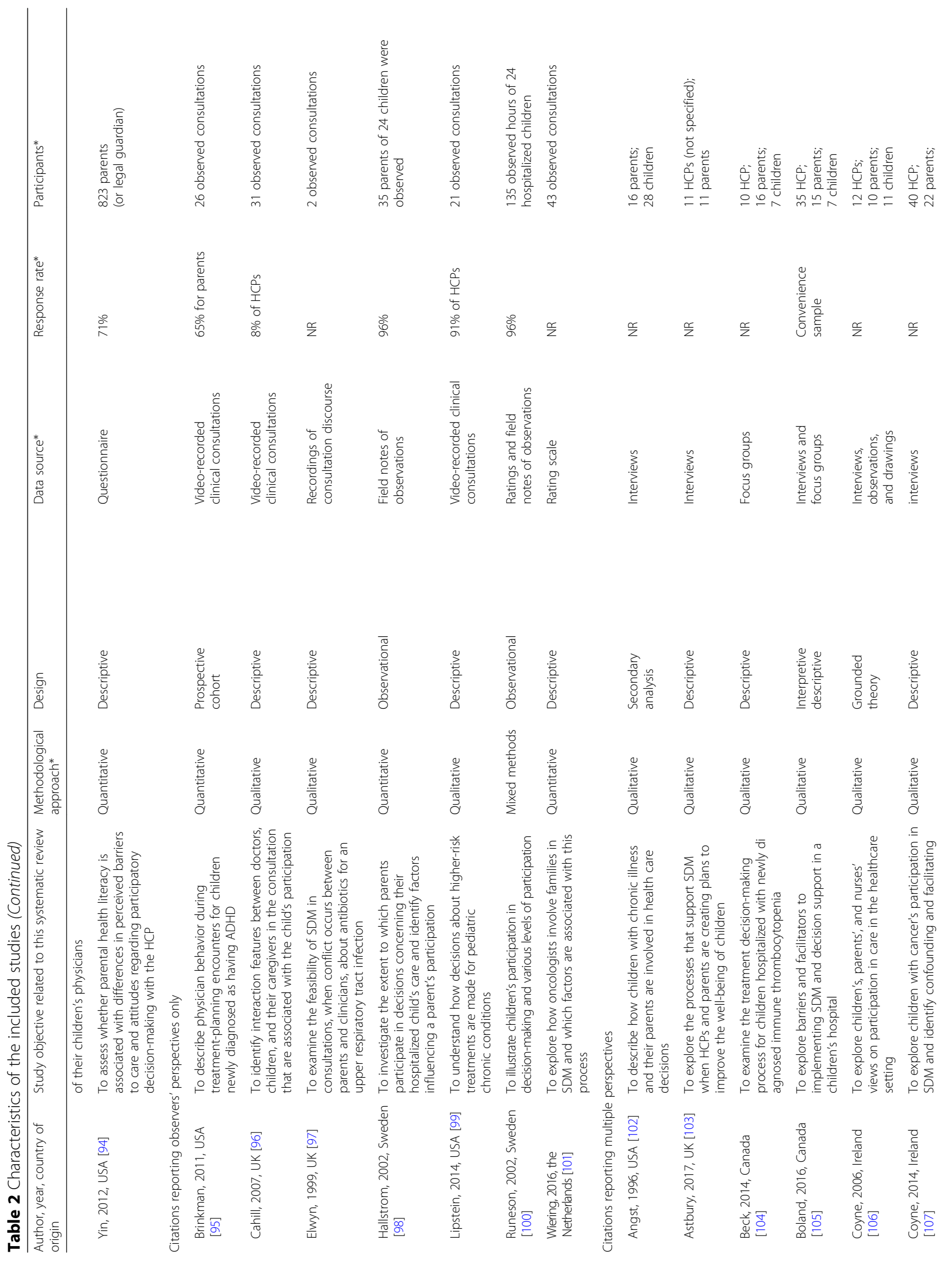




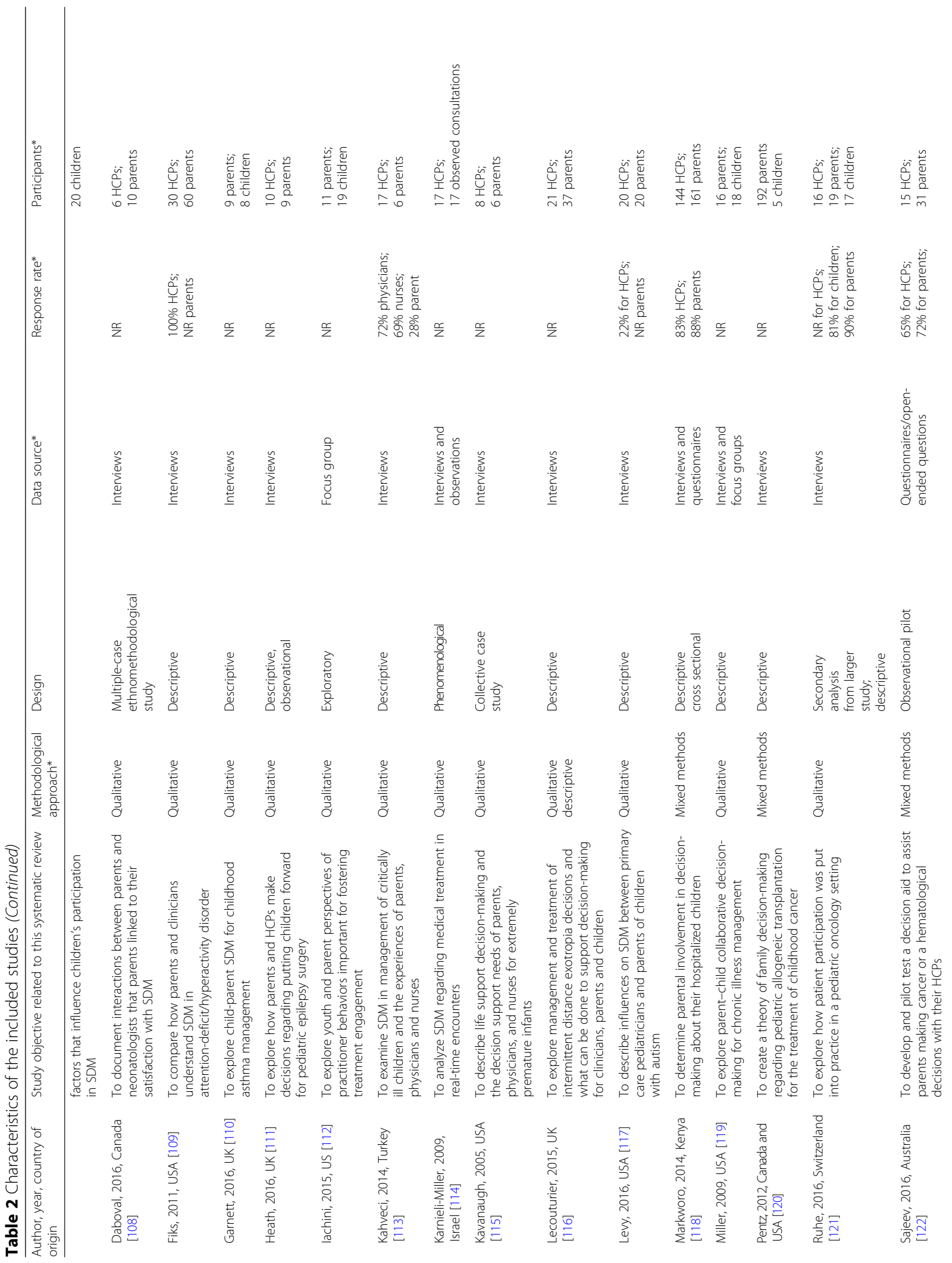




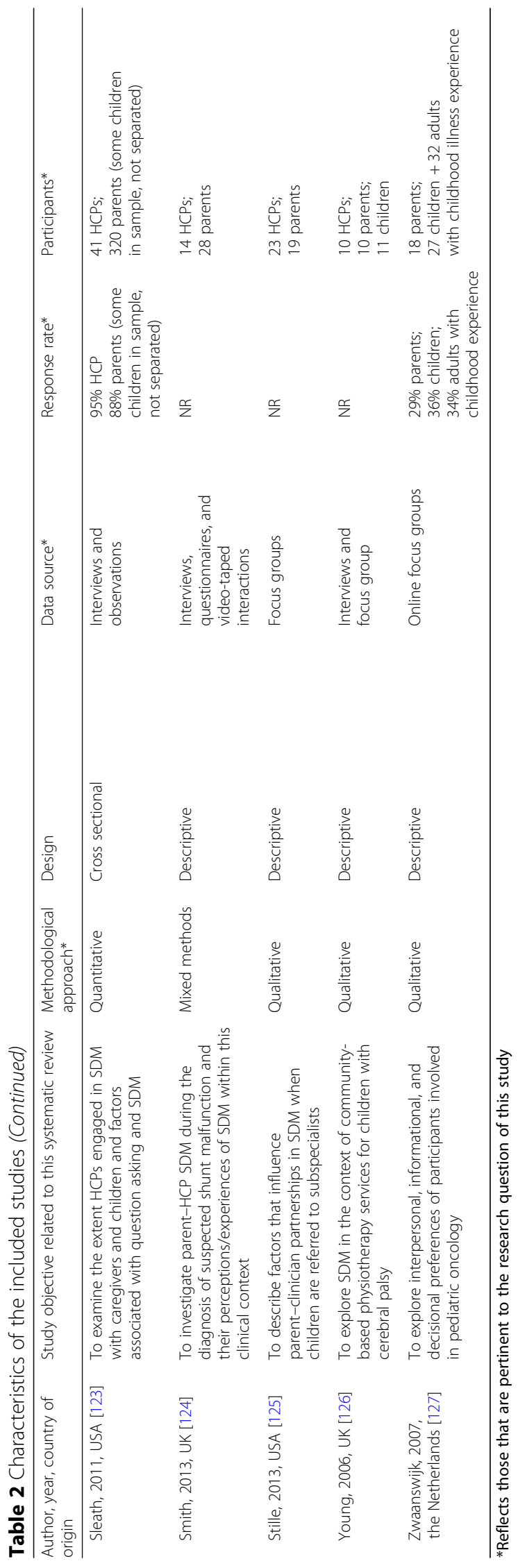




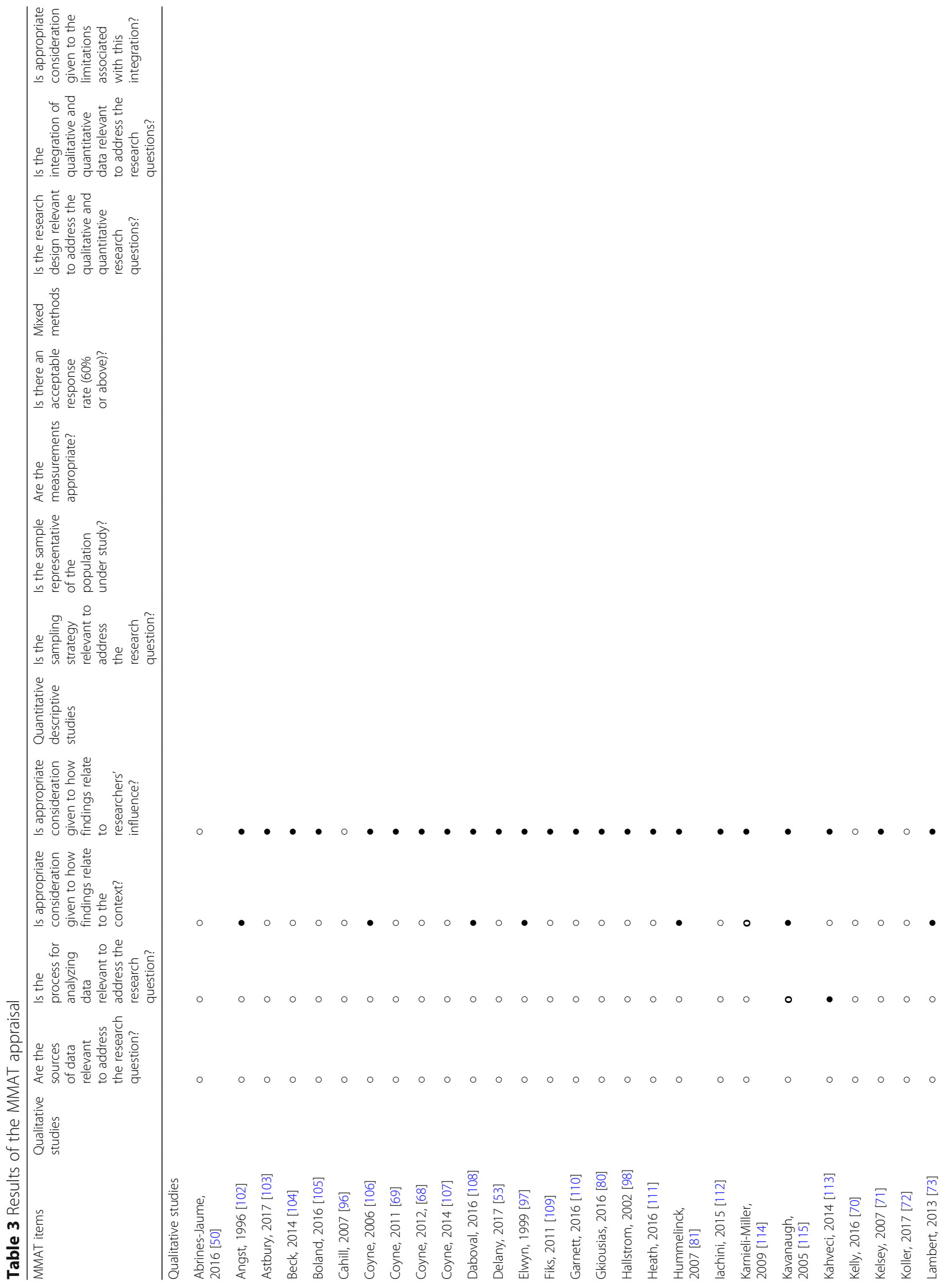




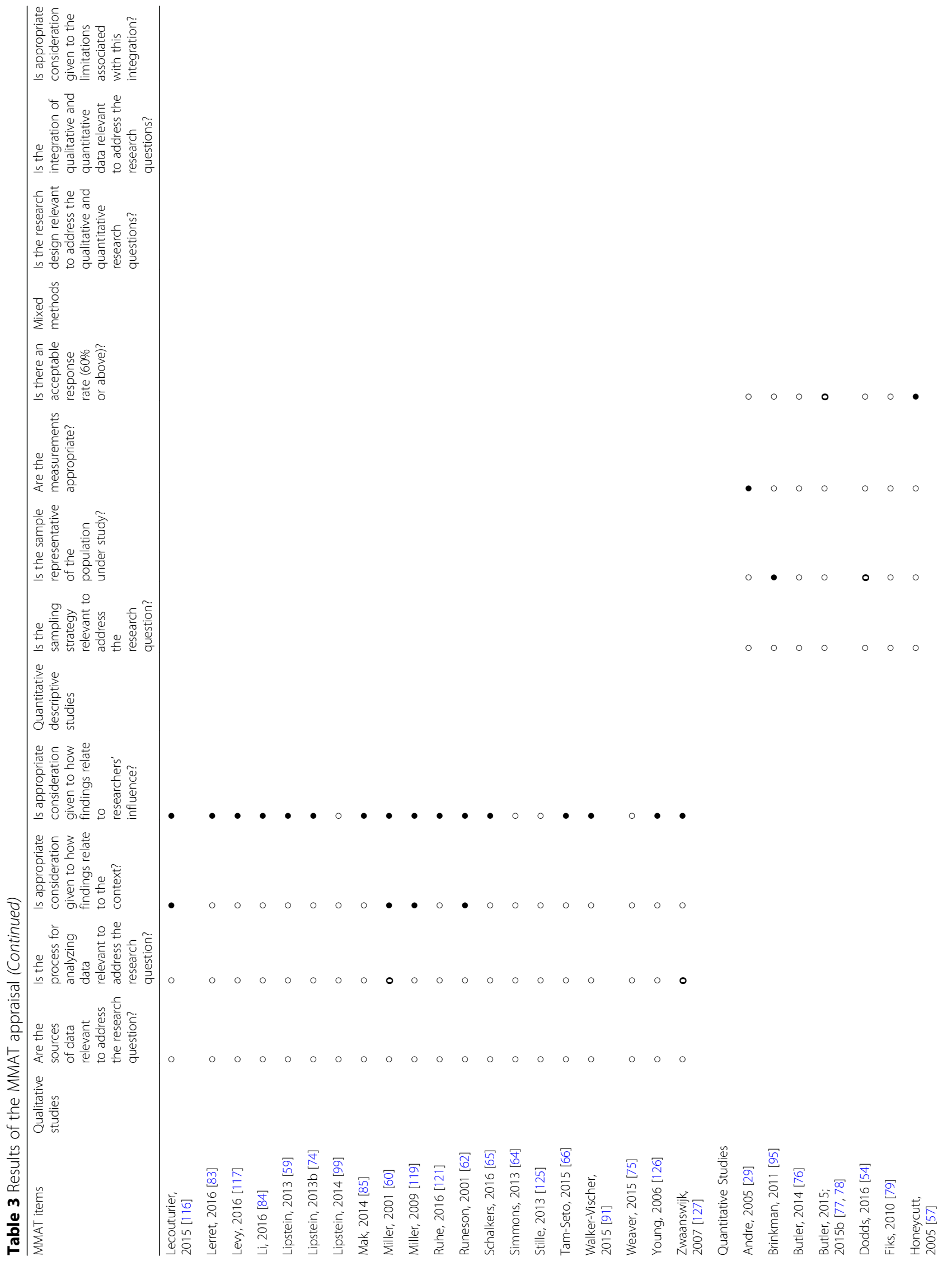







Table 4 Taxonomy and frequency counts of pediatric SDM barriers and facilitators from multiple perspectives

\begin{tabular}{|c|c|c|c|c|c|c|c|c|c|c|c|}
\hline \multirow{3}{*}{$\begin{array}{l}\text { Influencing factor (\# unique studies) } \\
\text { Decision level (19) }\end{array}$} & \multirow[t]{3}{*}{ Citations } & \multicolumn{10}{|c|}{ Barrier (B) and facilitator (F) (frequency counts) } \\
\hline & & \multicolumn{2}{|c|}{$\overline{\mathrm{HCP}}$} & \multicolumn{2}{|c|}{ Parent } & \multicolumn{2}{|c|}{ Children } & \multicolumn{2}{|c|}{ Observer } & \multicolumn{2}{|l|}{ Total } \\
\hline & & B & $\mathrm{F}$ & $B$ & $\mathrm{~F}$ & B & $\mathrm{F}$ & B & $\mathrm{F}$ & B & $\mathrm{F}$ \\
\hline Option features (11) & {$[67,70,84,99,109,116,117,119,120,124,125]$} & 4 & & 7 & & 3 & 2 & & 1 & 14 & 3 \\
\hline High versus low stake decisions (9) & {$[43,46,49,50,52,84,87,99,101]$} & 2 & 3 & 1 & 2 & 1 & 4 & & & 4 & 9 \\
\hline Availability of medical and research information (8) & {$[67,70,84,99,107,117,119,120,124,125]$} & & & 4 & & 1 & 2 & & & 5 & 2 \\
\hline Atypical decision or uncomfortable topics (2) & {$[64,119]$} & 1 & 1 & & & & 1 & & & 1 & 1 \\
\hline Totals & & 7 & 3 & 12 & 2 & 5 & 9 & & 1 & 24 & 15 \\
\hline Innovation level (i.e., SDM) (34) & & B & $\mathrm{F}$ & B & $\mathrm{F}$ & B & $\mathrm{F}$ & B & $\mathrm{F}$ & B & $\mathrm{F}$ \\
\hline $\begin{array}{l}\text { Level of quality/tailored information that is given } \\
\text { to the family (30) }\end{array}$ & $\begin{array}{l}{[54,59,60,64,68-70,72,73,75,80,82-84,91,92,} \\
96,97,102,104,106,108,109,111,112,115 \\
116,121,124,125]\end{array}$ & & 8 & 4 & 11 & 8 & 9 & 1 & 1 & 13 & 31 \\
\hline Impact of SDM on time (7) & {$[50,56,64,65,104,105,116]$} & 5 & 2 & & & & 1 & & & 5 & 3 \\
\hline Totals & & 5 & 10 & 4 & 11 & 8 & 10 & 1 & 1 & 18 & 34 \\
\hline Adopter level (i.e., HCP, parent, and child) (70) & & B & $\mathrm{F}$ & B & $\mathrm{F}$ & B & $\mathrm{F}$ & B & $\mathrm{F}$ & B & $\mathrm{F}$ \\
\hline \multicolumn{12}{|l|}{ Attitudes (43) } \\
\hline Agree with/desire for SDM/DM involvement (31) & $\begin{array}{l}{[58,60,64,67-70,72-75,80,81,83,85-88,94} \\
102,106,109,112,113,116,119,121 \\
124,125,127]\end{array}$ & 1 & 5 & 2 & 15 & 7 & 11 & & & 10 & 31 \\
\hline Beliefs about consequences (7) & {$[29,30,32,50,85,99,93,95,104]$} & & 4 & & 3 & 1 & 3 & & & 1 & 10 \\
\hline $\begin{array}{l}\text { Parents/children cannot understand } \\
\text { information (6) }\end{array}$ & {$[56,64,70,91,105,115]$} & 5 & & 1 & & & & & & 6 & \\
\hline Beliefs about capabilities (6) & {$[59,61,64,81,103,113,124]$} & 3 & 2 & 2 & 1 & 1 & & & & 6 & 4 \\
\hline Motivation (5) & {$[50,51,56,105,125]$} & 3 & 2 & 1 & 1 & 1 & & & & 5 & 3 \\
\hline Knowledge of SDM, policy (4) & {$[29,58,105,118]$} & 4 & & 2 & & 1 & & & & 7 & \\
\hline Satisfied with current DM approach (3) & {$[105,107,124]$} & 1 & & 1 & & 2 & & & & 4 & \\
\hline \multicolumn{12}{|l|}{ Characteristics of the adopters (59) } \\
\hline Child/parent health status (17) & $\begin{array}{l}{[38,43,44,46,48,50,51,54,56-59,64,65,69} \\
70,75,87,90,99,101]\end{array}$ & 3 & 3 & 5 & 3 & 3 & 3 & & 1 & 11 & 10 \\
\hline Parent/child's emotional state (16) & $\begin{array}{l}{[29,34,38,41,46,55,64,66,67,77,84,87,93} \\
95,96,99]\end{array}$ & 5 & 5 & 5 & 1 & 3 & & 1 & & 14 & 6 \\
\hline Child's age and competence (15) & {$[29,37,38,42-44,48,52-54,70,86,87,96,99]$} & 4 & 6 & & 1 & 4 & 2 & & & 8 & 9 \\
\hline HCP's SDM skills (14) & {$[29,64,66,68,69,75,95,97,99-101,108,116,124]$} & 3 & 3 & & 1 & 2 & 1 & 5 & & 10 & 5 \\
\hline $\begin{array}{l}\text { Parent/child race, ethnicity, culture, and } \\
\text { language (7) }\end{array}$ & {$[58,67,89,93,95,103,125]$} & 3 & 2 & 2 & & & & 1 & 1 & 6 & 2 \\
\hline Parent socioeconomic status (7) & {$[88-90,93,95,104,118]$} & & 2 & 1 & 3 & & & & 1 & 1 & 6 \\
\hline HCP age/seniority/specialty (6) & {$[57,58,61,73,90,123]$} & 1 & 3 & & & 1 & & 1 & & 3 & 3 \\
\hline Child's behavior/maturity (6) & {$[58,67,68,79,107,119]$} & & 3 & 2 & 1 & 1 & & & & 3 & 4 \\
\hline Parent's health insurance (5) & {$[54,59,89,93,95,109]$} & 1 & 1 & 2 & & & & 1 & & 4 & 1 \\
\hline HCPs role as advocate (6) & {$[60,73,91,111,113,115]$} & 1 & 3 & & 2 & & 1 & & & 1 & 6 \\
\hline Child experience with condition (4) & {$[67,69,72,104]$} & & 2 & & & & 2 & & & & 4 \\
\hline $\begin{array}{l}\text { HCP assuming parent/child preference } \\
\text { for involvement (3) }\end{array}$ & {$[61,85,112]$} & 1 & & 1 & & 1 & & & & 3 & \\
\hline Parental absence during SDM discussion (2) & {$[73,110]$} & & & & & & 2 & & & & 2 \\
\hline Parent health literacy (2) & {$[94,125]$} & 1 & & 2 & & & & & & 3 & \\
\hline Parent's sex or gender (2) & {$[108,123]$} & & & & 1 & & & & 1 & & 2 \\
\hline Totals & & 39 & 44 & 29 & 33 & 28 & 25 & 9 & 4 & 111 & 108 \\
\hline Relational level (i.e., social influences) (49) & & B & $\mathrm{F}$ & B & $\mathrm{F}$ & B & $\mathrm{F}$ & B & $\mathrm{F}$ & B & $\mathrm{F}$ \\
\hline Trust and respect in relationship (29) & $\begin{array}{l}{[30,34,41,46,49,50,52,55,61,63-68,71,72} \\
75,80,82,84,87-89,92,96,99,104,105]\end{array}$ & 2 & 7 & 2 & 13 & 1 & 7 & & 1 & 5 & 28 \\
\hline $\begin{array}{l}\text { Extent adopters invite/support parent/child } \\
\text { participation in DM (23) }\end{array}$ & $\begin{array}{l}{[29,60,66,69-71,75,83,92,94,96,98,102} \\
107-109,111,112,115-117,123,124]\end{array}$ & 1 & 4 & 3 & 8 & 1 & 4 & 2 & 1 & 7 & 17 \\
\hline
\end{tabular}


Table 4 Taxonomy and frequency counts of pediatric SDM barriers and facilitators from multiple perspectives (Continued)

\begin{tabular}{|c|c|c|c|c|c|c|c|c|c|c|c|}
\hline \multirow{3}{*}{$\begin{array}{l}\text { Influencing factor (\# unique studies) } \\
\text { Power relations (17) }\end{array}$} & \multirow{3}{*}{$\begin{array}{l}\text { Citations } \\
\begin{array}{l}{[66,68-70,73,81,87,96,106,107,110,111} \\
114,116,119,121]\end{array}\end{array}$} & \multicolumn{10}{|c|}{ Barrier (B) and facilitator (F) (frequency counts) } \\
\hline & & \multicolumn{2}{|l|}{$\overline{\mathrm{HCP}}$} & \multicolumn{2}{|c|}{ Parent } & \multicolumn{2}{|c|}{ Children } & \multicolumn{2}{|c|}{ Observer } & \multicolumn{2}{|c|}{ Total } \\
\hline & & 3 & & 3 & 1 & 9 & 1 & 1 & & 16 & 2 \\
\hline Biasing other adopters (12) & {$[58,59,64,74,97,99,104,109,119,120]$} & 5 & & 1 & & 2 & & 3 & & 11 & \\
\hline Recognition of HCP/parent expertise (6) & {$[72,81,86,87,112,124]$} & & 1 & 1 & 4 & 1 & & & & 2 & 5 \\
\hline Conflict (3) & {$[64,116,119]$} & 1 & & 2 & & 1 & & & & 4 & \\
\hline Totals & & 12 & 12 & 12 & 26 & 15 & 12 & 6 & 2 & 45 & 52 \\
\hline Environmental level (37) & & B & $\mathrm{F}$ & B & $\mathrm{F}$ & B & $\mathrm{F}$ & B & $\mathrm{F}$ & B & $\mathrm{F}$ \\
\hline Time (11) & {$[29,62-64,69,105,107,109,119,124,125]$} & 8 & 1 & 2 & & 2 & & & & 12 & 1 \\
\hline $\begin{array}{l}\text { Access to tools/resources/training to } \\
\text { promote SDM (10) }\end{array}$ & {$[52,53,55,56,65,67,82,103,104,122,125]$} & 4 & 6 & & 2 & & 1 & & & 4 & 10 \\
\hline Workflow and continuity of care (10) & {$[63,69,84,104,105,109,115-117,125]$} & 8 & 2 & 2 & & 1 & & & & 11 & 2 \\
\hline $\begin{array}{l}\text { Norms (e.g., organizational policy consistent } \\
\text { with SDM, expectations that HCP make } \\
\text { the decision) (11) }\end{array}$ & {$[29,64,68,74,94,104,105,107,113,126]$} & 5 & 2 & 3 & 1 & 4 & 1 & & & 12 & 4 \\
\hline $\begin{array}{l}\text { Clinical setting (e.g., emergency room) or } \\
\text { situation (e.g., urgency) (8) }\end{array}$ & {$[29,58,87,104,105,107,114,127]$} & 4 & 2 & 3 & 1 & 1 & & & & 8 & 3 \\
\hline Physical arrangement (e.g., seating) (3) & {$[96,104,124]$} & 1 & & & & 1 & & & 1 & 2 & 1 \\
\hline Stability of home environment (2) & {$[59,119]$} & 1 & & 1 & & & 1 & & & 2 & 1 \\
\hline Totals & & 31 & 13 & 11 & 4 & 9 & 3 & & 1 & 50 & 22 \\
\hline
\end{tabular}

*Qual qualitative, Quant quantitative, $M M$ mixed methods, $B$ barrier, $F$ facilitator, $H C P$ healthcare provider, SDM shared decision-making

\section{Innovation level (i.e., SDM; $n=34$ studies)}

Barriers All participant types reported that poor quality information about the condition and/or options that were inappropriately tailored to the child and family's health literacy needs hindered SDM (Table 4). Additionally, HCPs reported that engaging in the SDM process required too much time and, therefore, lacked feasibility in the pediatric clinical setting.

Facilitators The most commonly cited facilitator for pediatric SDM was high-quality information that was appropriately tailored to the child's developmental needs and the child/parent literacy needs (e.g., provided in lay terms). High-quality information included the presentation of options, their associated risks and benefits, and research evidence. Some HCPs and children also reported the potential for SDM to improve the way time was used in the clinical encounter.

\section{Adopter level (i.e., HCPs, parents, children; $n=70$ studies)}

Barriers Parent's and child's emotional state was the most commonly reported barrier at the adopter level (Table 4). This was described to hinder the SDM process when the parent and/or child felt overwhelmed, anxious, in denial, or defensive. Similarly, perceptions of poorer health status of the parent and/or child affected whether they were included, or wanted to be included, in decision-making. Some studies showed that children lacked agreement with SDM in principle and did not prefer SDM to traditional (patriarchal) decision-making approaches. Often HCPs lacked SDM skills, such as knowing how or when to elicit and incorporate family values and preferences in the decision-making process. Lack of HCP skill for SDM was the most frequently cited barrier reported by observers.

Facilitators Agreement with, and desire for, a SDM approach was the most commonly reported facilitator at the adopter level, reported by all adopters (Table 4), and was particularly important to parents. Adopters thought that SDM was the "right thing to do," that parent and child involvement was important, and that SDM would improve patient outcomes (e.g., satisfaction with the decision-making process). When parents and/or children were in good health, it facilitated efforts to include them in SDM as well as parent/child preference for participation. More efforts were made to include children who were older and perceived to have adequate decision-making competence, particularly among HCPs.

\section{Relational level ( $n=49$ studies)}

Barriers Power imbalance was the most cited relational barrier, and the most frequently cited by children (Table 4). Power imbalances were described as the systematic exclusion of children from the decision-making conversation or the child feeling too disempowered or intimidated to partner in SDM 
discussions. All participant types reported that deliberately biasing the opinion of another undermined the SDM process. This was often characterized as the HCP providing only one option, providing information on his or her preferred options only, using SDM to achieve compliance for his or her preferred option, or giving a specific recommendation.

Facilitators Trust and respect in relationships between adopters, primarily between HCPs and family, was a highly cited facilitator, and particularly important for parents. This was characterized by positive relationships, respectful communication, appreciation for each adopter's expertise, trusting that children will participate in meaningful ways, and that adopters will be open and forthcoming. All participant types reported that inviting and supporting the child and family throughout the SDM process was a facilitator.

\section{Environment level (i.e., pediatric clinical practice; $\boldsymbol{n}=37$ studies)}

Barriers Insufficient time due to heavy workloads was the main environmental barrier and the most cited by HCPs. Similarly, clinic workflow (e.g., integrating SDM into the care pathway) and poor continuity of care (e.g., high staff turnover) was reported to hinder SDM. Practice norms, such as the cultural expectation that a HCP's duty was to provide specific recommendations or make the decision, was a barrier, mostly reported by HCPs and children.

Facilitators The most common environmental facilitator, cited primarily by HCPs, was access to SDM tools (e.g., patient decision aids), resources (e.g., decision coaches or experts in SDM), and/or training.

\section{Factors influencing pediatric SDM and the OMRU}

To illustrate how barriers and facilitators can inform the implementation process, we mapped pediatric SDM influential factors (i.e., not separated into barriers and facilitators) to the OMRU (Fig. 4) [21]. Additionally, we tailored the OMRU for the pediatric SDM context by adding the decision and relational levels. The far left of the figure denotes our results for the assessment of pediatric SDM barriers and facilitators across various levels (i.e., decision, innovation, adopter, relational, and environment). The double arrows show that influencing factors are interrelated and dynamic. According to the OMRU, these influencing factors should inform the development of implementation strategies designed to promote innovation use by minimizing barriers and leveraging facilitators. For example, effective patient decision aids designed for pediatric practice could enhance the high-quality information that is provided to families $[5,13]$. The middle column indicates these interventions or strategies should be monitored for impact and degree of use. Finally, the far right of the model shows that interventions should be evaluated for evidence of impact and innovation uptake. Given that the model is iterative, sustained innovation use may require ongoing barrier and facilitator assessments and/or additional implementation strategies (e.g., more of the same implementation strategies or new ones targeting emergent barriers) $[21,30]$.

\section{Discussion}

We conducted a systematic review of factors influencing pediatric SDM across OMRU levels and from the perspective of HCPs, parents, children, and observers. At each OMRU level, the most frequent barriers were features of the options (decision), poor quality and/or insufficiently tailored information (innovation), parent/child emotional state (adopter), power relations (relational), and insufficient time for SDM (environment). The most frequent facilitators were lower stake decisions (decision), good quality information that is tailored to the families' literacy and developmental needs (innovation), agreement with SDM (adopter), trust and respect in the relationship (relational), and SDM tools/resources (environment). Across participant types, the most frequently cited barriers were insufficient time (HCPs), features of the options (parents), power imbalances (children), and HCP skill for SDM (observers). The most frequently cited facilitators were good quality information that is tailored to the families' literacy and developmental needs (HCPs), and agreement with and desire for SDM (parents and children). There was no consistent facilitator category for observers. These findings lead us to make the following observations, which we report at each OMRU level (decision, innovation, adopter, relational, and environment).

At the decision level, antecedent influential factors can impact SDM before the process begins. For example, several adopters felt SDM was unnecessary when they perceived only one reasonable option. Similarly, the perceived magnitude of the decision (high or low stakes) influenced whether adopters attempted to include the child or whether the child wished to participate. To facilitate SDM, HCPs should disclose all reasonable options, including the option of doing nothing [31]. Parents and children reported needing to be invited to engage in SDM for both high and low stake decisions. Additionally, adopters could broaden their conceptualization of SDM from an information exchange process (i.e., HCPs provide the medical evidence and patients relay their preferences) to empowering the patient and family by enabling discussion and participation and providing support for deliberation about the best treatment option [32, 33]. 


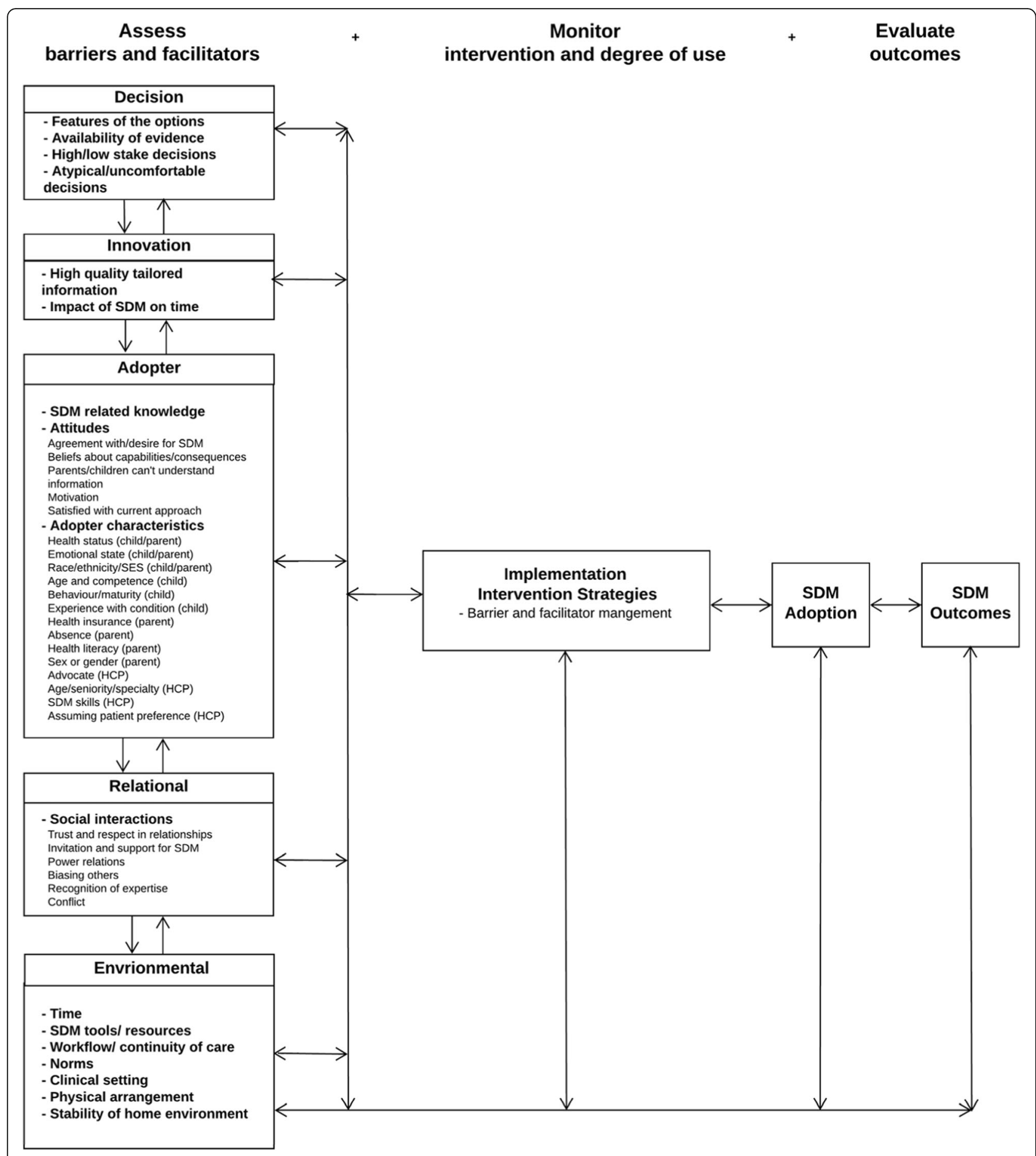

Fig. 4 Factors influencing SDM in pediatric clinical practice mapped to the OMRU. Adapted from Logan and Graham, 2010. Double arrows and feedback loops depict the interrelated nature of influential factors existing exist within a system. Influential factors can be present or absent

Our review identified few barriers at the innovation level, implying that adopters were generally satisfied with $\mathrm{SDM}$ as an innovation when they received high-quality information. However, HCPs reported that SDM took too much time. A Cochrane review that examined patient decision aids for supporting SDM found limited evidence that this SDM intervention took more time [13]. A pilot study evaluating decision coaching using a patient decision aid to prepare children and parents for SDM with their physician took a median of $35 \mathrm{~min}$ [34], though the time subsequently spent with the physician was not measured. Given the widespread perceptions about insufficient 
time for SDM, implementation interventions could emphasize that time spent on SDM is time spent differently, with the potential to increase downstream efficiencies, treatment adherence, and build decision-making capacity in children [35].

At the adopter level, our study showed that most HCPs, parents, and children had positive attitudes about SDM, recognizing that SDM led to positive outcomes for children and families and potentially the system. Nonetheless, some children expressed uncertainty about SDM's utility and preferred to avoid the burden of decision-making. HCPs and parents often assumed that younger children were unable to participate in SDM, and several HCPs reported that parents and children could not sufficiently understand the medical information needed to engage in decision-making. Yet, observers reported that HCPs lacked the skills needed to translate information and engage families in SDM, limiting parent's and children's opportunities to get high-quality information. Implementation interventions should emphasize that SDM is a partnership between adopters with shared responsibility for the decision. In contrast to autonomous decision-making, children can be empowered to participate to the extent they are able, through elicitation and consideration of their preferences and views [10]. Typically, informed consent for treatment is a legal requirement, yet unachievable if parents do not understand the information. Our findings suggest that pediatric $\mathrm{HCPs}$ require additional education, training, and support to ensure they have the skills to provide families with high-quality information they can understand and use during the SDM process.

At the relational level, our study showed that adopters frequently reported that power imbalances hindered SDM. Adopters recognized that children and parents have difficulty negotiating decision-making involvement and required HCPs' encouragement and support to participate. A systematic review that evaluated the impact SDM among disadvantaged groups (e.g., low literacy, minority, lower socioeconomic status) found that SDM interventions significantly improved outcomes for vulnerable populations, perhaps more so than individuals in higher literacy and socioeconomic situations [36]. As such other vulnerable groups, such as children, are good candidates for SDM [37]. Consistent with findings from another review that evaluated patient's perceived barriers to SDM in adult medicine [9], parents and children want to be empowered with an invitation to participate in SDM and high-quality information to enhance their knowledge for decision-making. As parents and children become more knowledgeable about their illness and healthcare system, they report increased capacity for SDM [29]. Our findings showed that an invitation to participate in decision-making should be supported with information that is consistent with the child's developmental stage and/or the parent's literacy level. This can be achieved by assessing health literacy levels and tailoring the information accordingly, using child-friendly and developmentally appropriate information, eliciting and incorporating the parent/child's preferences and values, and verified using teach-back methods [38-41]. Furthermore, trust and respect between $\mathrm{HCPs}$ and families can decrease power imbalances by making the parent and child more comfortable asking questions [42].

At the environment level, insufficient time to engage in the SDM process was the most commonly reported barrier, particularly by HCPs. This finding is consistent with HCP reports in another systematic review of SDM barriers in adult medicine [8]. Additionally, workflow and expectations that HCPs make the decision were commonly reported. A recent scoping review of environmental barriers and facilitators to SDM in adult practice recommends countering these predominant barriers by improving the distribution of HCP's workloads, decreasing pressure for short interactions with patients, and enhancing patient pathway flexibility and scheduling [43]. However, more research is needed to inform changing norms and cultural and societal expectations for SDM.

\section{Implications and suggestions for future work}

The findings of this review suggest that numerous barriers and facilitators influence the implementation of SDM and that each adopter type can experience or perceive different barriers and facilitators. Findings of a Cochrane review suggest that SDM interventions targeting the interprofessional team as well as patients could improve the adoption of SDM in clinical practice [15]. Although few interventions have been evaluated to promote SDM in pediatric clinical practice $[5,6]$, our review suggests that HCPs, parents, and children would benefit from evidence-based interventions that are specifically tailored to their perceived and/or experienced barriers and facilitators. Consistent with the OMRU, our taxonomy can inform the development of interventions that minimize pediatric SDM barriers and leverage facilitators to improve SDM use. Future research is also needed to examine the nature and strength of the relationships between influential factors to better understand the circumstances in which they interact within the healthcare system to impact SDM use in pediatric clinical practice.

Contextual factors are important for shaping decisions about policy development for health innovations [44]. To promote the uptake of SDM in pediatric clinical practice, decision-makers should consider the influential factors, including those relevant to their unique context, and create policies that aim to minimize barriers and leverage facilitators. For example, organizational policies can foster supportive SDM environments for HCPs, children, and 
parents [30]. Supportive environments could prioritize patient and family-centered care, partnerships with families, team-based care, decision support, as well as decrease pressure for minimum consultation lengths and incorporate SDM into their clinical practice guidelines and accreditation standards [45-47].

\section{Strengths and limitations}

To our knowledge, this is the first systematic review to focus on the barriers and facilitators of SDM in pediatric clinical practice and is strengthened by the presentation of multiple perspectives (i.e., HCPs, parents, children, and observers) structured using a theoretical implementation model (OMRU). However, several limitations should be considered. Meta-analysis was not possible due to heterogeneity across methodological approaches and measures in the quantitative studies. Therefore, we conducted a narrative synthesis. Due to the large number of included studies with qualitative and quantitative data, we synthesized barriers and facilitators using counting techniques, therefore, not accounting for the effect size. Researcher influence inherently impacts the analysis of qualitative data. At the level of a systematic review, participant-reported data is subject to third reviewer interpretation (those of the original authors and ours), therefore, posing a fidelity risk between the participants' original statement and our interpretations [48]. Notably, many studies originated from the USA (44\%), potentially reflecting barriers and facilitators that are unique to the US healthcare system. For example, features of the options and parental health insurance were often cited by US studies. As such, not all influential factors are relevant or applicable to all contexts. Although we critically appraised included studies and reported potential sources of bias (overall and individually), we did not perform a sensitivity analysis. As such, it is possible that highly biased evidence was given undue weight and low biased studies were underemphasized [49]. Finally, our search was conducted in 2017. Given that our review included 79 studies, it is less likely that newly published studies will have a significant impact on our findings.

\section{Conclusions}

Our study synthesized the barriers and facilitators of implementing SDM in pediatric practice. Pediatric SDM is gaining interest and momentum among researchers with an increasing number of relevant publications each year. Indeed, numerous and diverse barriers and facilitators influence HCPs, parents, and children's ability to use SDM in pediatric clinical practice. Our study provides a foundation for improved understanding of the factors influencing pediatric SDM use and how to manage them. Future research can use our taxonomy to inform the selection, tailoring, and/or development of knowledge translation interventions to promote SDM in pediatric clinical practice. Policy makers should also consider the context influencing SDM use in pediatrics to reduce barriers and leverage facilitators. Such efforts could improve the health of children by supporting and empowering them to engage in SDM and make high-quality decisions that are consistent with their informed values and preferences.

\section{Additional file}

Additional file 1: CINAHL electronic search. (DOCX $133 \mathrm{~kb})$

\section{Acknowledgements}

Anton Saarimaki designed the systematic review web screening application and provided technical support. Sophia Siedlikowski extracted data from several studies. Intissar Souli extracted data and appraised several studies.

Financial disclosure

All authors declare they have no financial relationships related to this article to disclose.

\section{Funding}

This research was funded by a Queen Elizabeth II Graduate Scholarship in Science and Technology and a Doctoral Fellowship from the Canadian Institutes of Health Research funded Integrated Knowledge Translation Research Network (CIHR FDN \#143237). IDG is a recipient of a Canadian Institutes of Health Research Foundation Grant (FDN \#143237). JJ and KL were supported by a Canadian Institutes of Health Research Fellowship Awards. DS was supported by a University Research Chair in knowledge translation to patients and FL was supported by a Canadian Research Chair in shared decision-making and knowledge translation.

Availability of data and materials

All data used in this study are available in the included primary studies.

\section{Authors' contributions}

LB led and participated in all phases of the study, including conceptualization and design, screening, data extraction, synthesis, and interpretation. She also drafted the manuscript. IDG participated in study conceptualization and design, data synthesis, and interpretation. He revised and approved the final manuscript. FL participated in the study conceptualization and design and interpretation of the synthesized data. She revised and approved the final manuscript. $\mathrm{KL}$ participated in all stages of study screening and the consensus process. She revised and approved the final manuscript. JJ participated in all stages of study screening and the consensus process. She revised and approved the final manuscript. AS participated in all stages of study screening and the consensus process. She revised and approved the final manuscript. ML participated in the study conceptualization and design. She revised and approved the final manuscript. $A D$, an information specialist, designed and conducted the search strategy. She revised and approved the final manuscript. AY participated in the data extractions, study appraisal, and the consensus process. She revised and approved the final manuscript. DS is the senior author for this study. She participated in the study conceptualization and design, screening, data synthesis, and interpretation, and she revised and approved the final manuscript. All authors approved the final manuscript as submitted and agree to be accountable for all aspects of the work.

Ethics approval and consent to participate

Not applicable.

Consent for publication

Not applicable.

Competing interests

All authors declare that they have no competing interests. 


\section{Publisher's Note}

Springer Nature remains neutral with regard to jurisdictional claims in published maps and institutional affiliations.

\begin{abstract}
Author details
${ }^{1}$ Faculty of Health Sciences, University of Ottawa, 540 King Edward Avenue, Ottawa, ON K1N 6N5, Canada. ${ }^{2}$ Ottawa Hospital Research Institute, 501 Smyth Road, Ottawa, ON K1H 8L6, Canada. ${ }^{3}$ School of Epidemiology and Public Health, Faculty of Medicine, University of Ottawa, 307D-600 Peter Morand Cresent, Ottawa, ON K1G 5Z3, Canada. ${ }^{4} \mathrm{CHU}$ de Québec Research Centre-Université Laval site Hôpital St-Francois d'Assise, 10 Rue Espinay, Quebec City, Quebec G1L 3L5, Canada. ${ }^{5}$ School of Rehabilitation Therapy, Faculty of Health Sciences, Queen's University, 31 George Street Kingston, Ottawa, ON K7L 3N6, Canada. ${ }^{6}$ Children's Hospital of Eastern Ontario, 401 Smyth Road, Ottawa, ON K1H 8L1, Canada. 'Learning Services, The Ottawa Hospital, 1053 Carling Ave, Ottawa, ON K1Y 4E9, Canada.
\end{abstract}

Received: 26 July 2018 Accepted: 27 December 2018

Published online: 18 January 2019

\section{References}

1. Légaré F, Stacey D, Pouliot S, et al. Interprofessionalism and shared decision-making in primary care: a stepwise approach towards a new model. J Interprof Care. 2011;25(1):18-25. https://doi.org/10.3109/13561820. 2010.490502.

2. Barry MJ, Edgman-Levitan S. Shared decision making - the pinnacle of patient-centered care. N Engl J Med. 2012;366(9):780-1.

3. Härter M, Moumjid N, Cornuz J, Elwyn G, van der Weijden T. Shared decision making in 2017: international accomplishments in policy, research and implementation. Z Evid Fortbild Qual Gesundhwes. 2017;123-124:1-5. https://doi.org/10.1016/j.zefq.2017.05.024.

4. Harrison C. Treatment decisions regarding infants, children and adolescents. Position statement Paediatr Child Heal Can Pediatr Soc. 2004;9(2):99-103. https://www.ncbi.nlm.nih.gov/pmc/articles/PMC2720471/.

5. Wyatt KD, List B, Brinkman WB, et al. Shared decision making in pediatrics: a systematic review and meta-analysis. Acad Pediatr. 2015;15(6):573-83. https://doi.org/10.1016/j.acap.2015.03.011.

6. Feenstra B, Boland L, Lawson ML, et al. Interventions to support children's engagement in health-related decisions: a systematic review. BMC Pediatr. 2014;14(1):109. https://doi.org/10.1186/1471-2431-14-109.

7. Baker R, Camosso-Stefinovic J, Gillies C, et al. Tailored interventions to overcome identified barriers to change: effects on professional practice and health care outcomes. Cochrane Database Syst Rev. 2010;3:Cd005470. https://doi.org/10.1002/14651858.CD005470.pub2.

8. Légaré F, Ratté S, Gravel K, Graham ID. Barriers and facilitators to implementing shared decision-making in clinical practice: update of a systematic review of health professionals' perceptions. Patient Educ Couns. 2008;73(3):526-35. https://doi.org/10.1016/j.pec.2008.07.018.

9. Joseph-Williams N, Elwyn G, Edwards A. Knowledge is not power for patients: a systematic review and thematic synthesis of patient-reported barriers and facilitators to shared decision making. Patient Educ Couns. 2014;94(3):291-309. https://doi.org/10.1016/j.pec.2013.10.031.

10. Gabe J, Olumide G, Bury M. It takes three to tango: a framework for understanding patient partnership in paediatric clinics. Soc Sci Med. 2004; 59(5):1071-9.

11. Lipstein EA, Brinkman WB, Fiks AG, et al. An emerging field of research: challenges in pediatric decision making. Med Decis Mak. 2015;35(3):403-8. https://doi.org/10.1177/0272989X14546901.

12. Godin G, Belanger-Gravel A, Eccles M, Grimshaw J. Healthcare professionals' intentions and behaviours: a systematic review of studies based on social cognitive theories. Implement Sci. 2008;3:36. https://doi. org/10.1186/1748-5908-3-36

13. Stacey $D$, Légaré $F$, Lewis $K$, et al. Decision aids for people facing health treatment or screening decisions. Cochrane Database Syst Rev. 2017;4: CD001431. https://doi.org/10.1002/14651858.CD001431.pub5.

14. Stacey D, Kryworuchko J, Bennett C, et al. Decision coaching to prepare patients for making health decisions: a systematic review of decision coaching in trials of patient decision aids. Med Decis Mak. 2012;32:E22-33. https://doi.org/10.1177/0272989X12443311.

15. Légaré $F$, Adekpedjou $R$, Turcotte $S$, et al. Interventions for improving the adoption of shared decision making by healthcare professionals. Cochrane
Database Syst Rev. 2018;19(7):CD006732. https://doi.org/10.1002/14651858. CD006732.pub4.

16. Shields L, Zhou H, Pratt J, Taylor M, Hunter JPE. Family-centred care for hospitalised children aged 0-12 years. Cochrane Database Syst Rev. 2012. https://doi.org/10.1002/14651858.CD004811.pub3.

17. Coyne I, O'Mathuna DP, Gibson F, Shields L, Leclercq E, Sheaf G Interventions for promoting participation in shared decision-making for children with cancer. Cochrane Database Syst Rev. 2016;6:CD008970.

18. Higgins J, Green S. Cochrane handbook for systematic reviews of interventions version 5.1.0.; 2011. https://training.cochrane.org/handbook.

19. Moher D, Liberati A, Tetzlaff J, Altman DG. The PRISMA Group. Preferred reporting items for systematic reviews and meta-analyses: the PRISMA Statement. Open Med. 2009;3(2):123-30.

20. Boland L, Lewis K, Jull J, et al. Barriers and facilitators of shared decision making in pediatric clinical practice: a systematic review. PROSPERO. http:// www.crd.york.ac.uk/PROSPERO/display_record.php?ID=CRD42015020527.

21. Logan J, Graham ID. The Ottawa model of research use. In: Rycroft-Malone JBT, editor. Models and frameworks for implementing evidence-based practice: linking evidence to action. Oxford: Wiley-Blackwell; 2010. p. 83-108.

22. Légaré $F$, Witteman $\mathrm{HO}$. Shared decision making: examining key elements and barriers to adoption into routine clinical practice. Health Aff. 2013;32(2): 276-84. https://doi.org/10.1377/hlthaff.2012.1078.

23. Schardt C, Adams MB, Owens T, Keitz S, Fontelo P. Utilization of the PICO framework to improve searching PubMed for clinical questions. BMC Med Inform Decis Mak. 2007;7:16.

24. Gravel K, Légaré F, Graham ID. Barriers and facilitators to implementing shared decision-making in clinical practice: a systematic review of health professionals' perceptions. Implement Sci. 2006;1(1):16-32. https://doi.org/ 10.1186/1748-5908-1-16

25. Hsieh H-F, Shannon SE. Three approaches to qualitative content analysis. Qual Health Res. 2005;15(9):1277-88. https://doi.org/10.1177/1049732305276687.

26. Bengtsson M. How to plan and perform a qualitative study using content analysis. NursingPlus Open. 2016;2:8-14. https://doi.org/10.1016/j.npls.2016.01.001.

27. Pluye P, Gagnon MPGF, Johnson-Lafleur J. A scoring system for appraising mixed methods research, and concomitantly appraising qualitative, quantitative and mixed methods primary studies in mixed studies reviews. Int J Nurs Stud. 2009;46(4):529-46.

28. Souto RQ, Hong QN, Bush PL, Vedel I, Pluye P. Systematic mixed studies reviews: updating results on the reliability and efficiency of the mixed methods appraisal tool. Int J Nurs Stud. 2015;52(1):500-1.

29. André N, Gaudart J, Bernard J, Chabrol B. Quelle place pour l'enfant dans la prise de décision en pédiatrie? Arch Pediatr. 2005;12:1068-74. https://doi. org/10.1016/j.arcped.2005.02.009.

30. Boland L, Lawson M, Graham ID, Legare F, Dorrance K, Shephard A, Stacey D. Post-training shared decision making barriers and facilitators for pediatric healthcare providers: a mixed-methods study. Acad Pediatr. 2018; Epub ahead.

31. Joseph-Williams N, Edwards A, Elwyn G. Preparing patients ahead of time to share decisions about their health care. In: Shared decision making in health care. Oxford: Oxford University Press; 2016. p. 43-50.

32. Charles C, Gafni A, Whelan T. Shared decision-making in the medical encounter: what does it mean? Soc Sci Med. 1997:44:681-92.

33. Entwistle VA, Watt IS. Broad versus narrow shared decision making. In: Shared decision making in health care: Oxford University Press; 2016. p. $7-$ 12. https://doi.org/10.1093/acprof:oso/9780198723448.003.0002.

34. Feenstra B, Lawson ML, Harrison D, Boland L, Stacey D. Decision coaching using the Ottawa family decision guide with parents and their children: a field testing study. BMC Med Inform Decis Mak. 2015;15(1). https://doi.org/ 10.1186/s12911-014-0126-2.

35. Légaré $F$, Thompson-Leduc $P$. Twelve myths about shared decision making. Patient Educ Couns. 2014;96(3):281-6. https://doi.org/10.1016/j.pec.2014.06.014.

36. Durand MA, Dolan H, Bravo P, Mann M, Bunn F, Elwyn G. Do interventions designed to support shared decision making reduce health inequalities? A systematic review and meta-analysis. PLoS One. 2014;9(4):1-13.

37. Fiks AG, Jimenez ME. The promise of shared decision-making in paediatrics. Acta Paediatr. 2010;99:1464-6.

38. McCabe M. Involving children and adolescents in medical decision making: developmental and clinical considerations. J Pediatr Psychol. 1996;21(4):505-16.

39. Berlinger N, Barfield R, Fleischman AR. Facing persistent challenges in pediatric decision-making: new Hastings Center Guidelines. Pediatrics. 2013; 132(5):789-91. https://doi.org/10.1542/peds.2013-1378. 
40. Sanders LM, Shaw JS, Guez G, Baur C, Rudd R. Health literacy and child health promotion: implications for research, clinical care, and public policy. Pediatrics. 2009;124(Supplement 3):S306-14. https:/doi.org/10.1542/peds.2009-1162G.

41. Batterham RW, Hawkins M, Collins PA, Buchbinder R, Osborne RH. Health literacy: applying current concepts to improve health services and reduce health inequalities. Public Health. 2016;132:3-12. https://doi.org/10.1016/j. puhe.2016.01.001.

42. Swedlund MP, Schumacher JB, Young HN, Cox ED. Effect of communication style and physician-family relationships on satisfaction with pediatric chronic disease care. Health Commun. 2012;27(5):498-505. https://doi.org/ 10.1080/10410236.2011.616632.

43. Scholl I, LaRussa A, Hahlweg P, Kobrin S, Elwyn G. Organizational- and system-level characteristics that influence implementation of shared decision-making and strategies to address them - a scoping review. Implement Sci. 2018;13(1):40. https://doi.org/10.1186/s13012-018-0731-z.

44. Bosch-Capblanch X, Lavis JN, Lewin S, et al. Guidance for evidence-informed policies about health systems: rationale for and challenges of guidance development. PLoS Med. 2012;9:e1001185.

45. Committee Canadian DACPGE. Canadian Diabetes Association 2008 clinical practice guidelines for the prevention and management of diabetes in Canada. Can J Diabetes. 2008;32:S1-S201.

46. Grad R, Légaré F, Bell NR, Dickinson JA, Singh H, Moore AE, Kasperavicius D, Kretschmer K. Shared decision making in preventive health care: what it is; what it is not. Can Fam Physician. 2017:63:682-4.

47. Australian Commission on Safety and Quality in Health Care. National Safety and Quality Health Services Standards. 2nd ed. Sydney: ACSQHC; 2017

48. Ring N, Ritchie K, Mandava L, Jepson R. A guide to synthesizing qualitative research for researchers undertaking health technology assessments and systematic reviews; 2010.

49. Hannes K: Critical appraisal of qualitative research. In Supplementary guidance for inclusion of qualitative research in Cochrane systematic reviews of interventions. Cochrane C. Edited by Noyes J, Booth A, Hannes K, Harden A, Harris J, Lewin S LC.; 2011.

50. Abrines-Jaume N, Midgley N, Hopkins K, et al. A qualitative analysis of implementing shared decision making in child and adolescent mental health services in the United Kingdom: stages and facilitators. Clin Child Psychol Psychiatry. 2016;21(1):19-31. https://doi.org/10.1177/1359104514547596.

51. Bejarano C, Fuzzell L, Clay C, Leonard S, Shirley E, Wysocki T. Shared decision making in pediatrics: a pilot and feasibility project. Clin Pract Pediatr Psychol. 2015;3(1):25-36.

52. Boss RD, Hutton N, Donohue PK, Arnold RM. Neonatologist training to guide family decision making for critically ill infants. Arch Pediatr Adolesc Med. 2009;163(9):783-8. https://doi.org/10.1001/archpediatrics.2009.155.

53. Delany C, Xafis V, Gillam L, Hughson J, Hynson J, Wilkinson D. A good resource for parents, but will clinicians use it? Evaluation of a resource for paediatric end-of-life decision making. BMC Palliat Care. 2017;16:12. https:// doi.org/10.1186/s12904-016-0177-5.

54. Dodds CM, Britto MT, Denson LA, Lovell DJ, Saeed S, Lipstein EA. Physicians' perceptions of shared decision making in chronic disease and its barriers and facilitators. J Pediatr. 2016;171:307-9.e2. https://doi.org/10.1016/j.jpeds.2015.12.071.

55. Fay M, Grande SW, Donnelly K, Elwyn G. Using option grids: steps toward shared decision-making for neonatal circumcision. Patient Educ Couns. 2016;99(2):236-42. https://doi.org/10.1016/j.pec.2015.08.025

56. Frize M, Bariciak E, Gilchrist JPPADS. Physician-parent decision-support for neonatal intensive care. Stud Health Technol Inform. 2013;192:23-7.

57. Honeycutt C, Sleath B, Bush PJ, Campbell W, Tudor G. Physician use of a participatory decision-making style with children with $\mathrm{ADHD}$ and their parents. Patient Educ Couns. 2005;57:327-32. https://doi.org/10. 1016/j.pec.2004.09.004

58. Lee KJ, Havens PL, Sato T, Hoffman GM, Leuthner SR. Assent for treatment: clinician knowledge, attitudes, and practice. 2006;118(2):723-730. doi:https:// doi.org/10.1542/peds.2005-2830.

59. Lipstein EA, Brinkman WB, Sage J, Lannon CM, Morgan DeWitt E. Understanding treatment decision making in juvenile idiopathic arthritis: a qualitative assessment. Pediatr Rheumatol. 2013;11(1):34. https://doi.org/10 1186/1546-0096-11-34

60. Miller S. Facilitating decision-making in young people. Paediatr Nurs. 2001; 13(5):31-5.

61. Partridge JC. Intensive care for very low birthweight infants in South Africa: a survey of physician attitudes, parent counseling and resuscitation practices. J Trop Pediatr. 2005;51(1):11-6. https://doi.org/10.1093/tropej/fmh066.
62. Runeson I, Enskar K, Elander G, Hermerén G. Professionals' perceptions of children's participation in decision making in healthcare. J Clin Nurs. 2001; 10(1):70-8.

63. Schalkers I, Parsons CS, Bunders JF, Dedding C. Health professionals' perspectives on children's and young people's participation in health care: a qualitative multihospital study. J Clin Nurs. 2016;25(7-8):1035-44. https://doi. org/10.1111/jocn.13152.

64. Simmons MB, Hetrick SE, Jorm AF. Making decisions about treatment for young people diagnosed with depressive disorders: a qualitative study of clinicians' experiences. BMC Psychiatry. 2013;13(1):335. https://doi.org/10. 1186/1471-244X-13-335.

65. Shirley E, Bejarano C, Clay C, Fuzzell L, Leonard S, Wysocki T. Helping families make difficult choices. J Pediatr Orthop. 2014;0(0):1. https://doi.org/ 10.1097/BPO.0000000000000382.

66. Tam-Seto L, Versnel J. Occupational therapy shared decision making in adolescent mental health. Occup Ther Ment Heal. 2015;31(2):168-86. https:// doi.org/10.1080/0164212X.2015.1036194.

67. Vaknin O, Zisk-Rony RY. Including children in medical decisions and treatments: perceptions and practices of healthcare providers. Child Care Heal Dev. 2011;37(4):533-9. https://doi.org/10.1111/j.1365-2214.2010.01153.x.

68. Coyne I, Kirwan L. Ascertaining children's wishes and feelings about hospital life. J Child Heal Care. 2012;16(3):293-304. https://doi.org/10.1177/ 1367493512443905.

69. Coyne I, Gallagher P. Participation in communication and decision-making: children and young people's experiences in a hospital setting. J Clin Nurs. 2011:20(15-16):2334-43. https://doi.org/10.1111/j.1365-2702.2010.03582x.

70. Kelly KP, Mowbray C, Pyke-Grimm K, Hinds PS. Identifying a conceptual shift in child and adolescent-reported treatment decision making: "Having a say, as I need at this time..". Pediatr Blood Cancer. 2017;64(4):e26262. https://doi. org/10.1002/pbc.26262.

71. Kelsey J, Abelson-Mitchell N, Skirton H. Perceptions of young people about decision making in the acute healthcare environment. Paediatr Nurs. 2007; 19(6):14-8.

72. Koller D. "Kids need to talk too": inclusive practices for children's healthcare education and participation. J Clin Nurs. 2017;26(17-18):2657-68. https://doi. org/10.1111/jocn.13703.

73. Lambert V, Glacken M, McCarron M. Meeting the information needs of children in hospital. J Child Heal Care. 2013;17(4):338-53. https://doi.org/10. $1177 / 1367493512462155$

74. Lipstein EA, Muething KA, Dodds CM, Britto MT. "I'm the one taking it": adolescent participation in chronic disease treatment decisions. J Adolesc Health. 2013:53(2):253-9. https://doi.org/10.1016/j.jadohealth.2013.02.004.

75. Weaver MS, Baker JN, Gattuso JS, Gibson DV, Sykes AD, Hinds PS. Adolescents' preferences for treatment decisional involvement during their cancer. Cancer. 2015;121(24):4416-24. https://doi.org/10.1002/cncr.29663.

76. Butler AM. Shared decision-making, stigma, and child mental health functioning among families referred for primary care-located mental health services. Fam Syst Heal. 2014;32(1):116-21. https://doi.org/10.1037/ fsh0000004

77. Butler AM, Weller B, Titus C. Relationships of shared decision making with parental perceptions of child mental health functioning and care. Adm Policy Ment Heal Ment Heal Serv Res. 2015;42(6):767-74. https://doi.org/10. 1007/s10488-014-0612-y.

78. Butler AM, Elkins S, Kowalkowski M, Raphael JL. Shared decision making among parents of children with mental health conditions compared to children with chronic physical conditions. Matern Child Health J. 2015;19(2): 410-8. https://doi.org/10.1007/s10995-014-1523-y.

79. Fiks AG, Localio AR, Alessandrini EA, Asch DA, Guevara JP. Shared decisionmaking in pediatrics: a national perspective. Pediatrics. 2010;126(2):306-14. https://doi.org/10.1542/peds.2010-0526.

80. Gkiousias V, Butler CC, Shepherd V, et al. Parental perceptions and understanding of information provision, management options and factors influencing the decision-making process in the treatment of children with glue ear. Int J Pediatr Otorhinolaryngol. 2016;89:6-12. https://doi.org/10.1016/j.jporl.2016.07.021.

81. Hummelinck A, Pollock K. The relationship between healthcare professionals and the parents of chronically ill children: negotiating the boundaries between dependence and expertise. Int J Pharm Pract. 2007;15(1):3-9. https://doi.org/10.1211/ijpp.15.1.0002.

82. Kline C, Reineke A, Auger J, Willert J, Roberts W, Schiff D. Effects of a unique pediatric hematology-oncology palliative care program on medical decision-making and communication between healthcare providers and 
families: results of a supportive care survey. Prog Palliat Care. 2012;20(1):138. https://doi.org/10.1179/1743291X12Y.0000000002.

83. Lerret SM, Haglund KA, Johnson NL. Parents' perspectives on shared decision making for children with solid organ transplants. J Pediatr Heal Care. 2016;30(4):374-80. https://doi.org/10.1016/j.pedhc.2015.10.001.

84. Li KC, Birch PH, Garrett BM, MacPhee M, Adam S, Friedman JM. Parents' perspectives on supporting their decision making in genome-wide sequencing. J Nurs Scholarsh. 2016;48(3):265-75. https://doi.org/10.1111/jnu.12207.

85. Mack JW, Wolfe J, Cook EF, Grier HE, Cleary PD, Weeks JC. Parents' roles in decision making for children with cancer in the first year of cancer treatment. J Clin Oncol. 2011;29(15):2085-90. https:/doi.org/10.1200/JCO.2010.32.0507.

86. Mak L, Hiebert-Murphy D, Walker JR, Altman G. Parents' decision making and their information needs concerning treatments for child anxiety: implications for family-centered practice. J Fam Soc Work. 2014;17(1):51-67. https://doi.org/10.1080/10522158.2013.809671

87. Pyke-Grimm KA, Stewart JL, Kelly KP, Degner LF. Parents of children with cancer: factors influencing their treatment decision making roles. J Pediatr Nurs. 2006;21(5):350-61. https://doi.org/10.1016/j.pedn.2006.02.005

88. Rosati P, Di Salvo V, D'Amico R, et al. Outpatient parents' views on shareddecision-making at an Italian children's hospital. Health Promot Int. 2017:18. https://doi.org/10.1093/heapro/daw105.

89. Smalley LP, Kenney MK, Denboba D, Strickland B. Family perceptions of shared decision-making with health care providers: results of the National Survey of Children with Special Health Care Needs, 2009-2010. Matern Child Health J. 2014;18(6):1316-27. https://doi.org/10.1007/s10995-013-1365-z.

90. Valenzuela JM, Smith LB, Stafford JM, et al. Shared decision-making among caregivers and health care providers of youth with type 1 diabetes. I Clin Psychol Med Settings. 2014;21(3):234-43. https://doi.org/10.1007/s10880014-9400-9.

91. Walker-Vischer L, Hill C, Mendez SS. The experience of Latino parents of hospitalized children during family-centered rounds. JONA J Nurs Adm. 2015;45(3):152-7. https://doi.org/10.1097/NNA.0000000000000175.

92. Walter JK, Nestor K, Feudtner C. Parental perspectives on goals of care discussions with the healthcare team for their child with cancer. PsychoOncology. 2016;25(8):990-3. https://doi.org/10.1002/pon.3985.

93. Xu KT, Borders TF, Arif AA. Ethnic differences in parents' perception of participatory decision-making style of their children's physicians. Med Care. 2004;42(4):328-35. https://doi.org/10.1097/01.mlr.00001 18707.99818.cc.

94. Yin HS, Dreyer BP, Vivar KL, et al. Perceived barriers to care and attitudes towards shared decision-making among low socioeconomic status parents. Role of health literacy. Acad Pediatr. 2012;12(2):117-24. https://doi.org/10. 1016/j.acap.2012.01.001.

95. Brinkman WB. Physicians' shared decision-making behaviors in attentiondeficit/hyperactivity disorder care. Arch Pediatr Adolesc Med. 2011;165(11): 1013. https://doi.org/10.1001/archpediatrics.2011.154

96. Cahill P, Papageorgiou A. Video analysis of communication in paediatric consultations in primary care. Br J Gen Pract. 2007;57(544):866-71. https:// doi.org/10.3399/096016407782317838.

97. Elwyn G, Gwyn R, Edwards A, Grol R. Is "shared decision-making" feasible in consultations for upper respiratory tract infections? Assessing the influence of antibiotic expectations using discourse analysis. Health Expect. 1999;2(2): 105-17.

98. Hallström I, Runeson I, Elander G. An observational study of the level at which parents participate in decisions during their child's hospitalization Nurs Ethics. 2002;9(2):203-14. https://doi.org/10.1191/0969733002ne499oa.

99. Lipstein EA, Dodds CM, Britto MT. Real life clinic visits do not match the ideals of shared decision making. J Pediatr 2014;165(1):178-183.e1. doi: https://doi.org/10.1016/j.jpeds.2014.03.042

100. Runeson I, Hallstrom I, Elander G, Hermeren G. Children's participation in the decision-making process during hospitalization: an observational study. Nurs Ethics. 2002;9(6):583-98.

101. Wiering BM, Noordman J, Tates K, et al. Sharing decisions during diagnostic consultations; an observational study in pediatric oncology. Patient Educ Couns. 2016;99(1):61-7. https://doi.org/10.1016/..pec.2015.07.026.

102. Angst DB, Deatrick JA. Involvement in health care decisions: parents and children with chronic illness. J Fam Nurs. 1996;2(2):174-94.

103. Astbury R, Shepherd A, Cheyne H. Working in partnership: the application of shared decision-making to health visitor practice. J Clin Nurs. 2017;26(1-2): 215-24. https://doi.org/10.1111/jocn.13480.

104. Beck CE, Boydell KM, Stasiulis E, et al. Shared decision making in the management of children with newly diagnosed immune thrombocytopenia. J Pediatr Hematol Oncol. 2014;36(7):559-65. https://doi. org/10.1097/MPH.0000000000000120

105. Boland L, Mclsaac DI, Lawson ML. Barriers to and facilitators of implementing shared decision making and decision support in a paediatric hospital: a descriptive study. Paediatr Child Health. 2016;21(3):e17-21. https://doi.org/10.1093/pch/21.3.e17.

106. Coyne I. Consultation with children in hospital: children, parents' and nurses' perspectives. J Clin Nurs. 2006;15(1):61-71. https://doi.org/10.1111/j. 1365-2702.2005.01247.x.

107. Coyne I, Amory A, Kiernan G, Gibson F. Children's participation in shared decision-making. Children, adolescents, parents and healthcare professionals' perspectives and experiences. Eur J Oncol Nurs. 2014;18(3): 273-80. https://doi.org/10.1016/j.ejon.2014.01.006.

108. Daboval T, Shidler S, Thomas D. Shared decision making at the limit of viability: a blueprint for physician action. Lavoie PM, ed. PLoS One 2016; 11(11):e0166151. doi:https://doi.org/10.1371/journal.pone.0166151.

109. Fiks AG, Hughes CC, Gafen A, Guevara JP, Barg FK. Contrasting parents' and pediatricians' perspectives on shared decision-making in ADHD. Pediatrics. 2011;127(1):e188-96. https://doi.org/10.1542/peds.2010-1510.

110. Garnett V, Smith J, Ormandy P. Child-parent shared decision making about asthma management. Nurs Child Young People. 2016;28(4):16-22. https:// doi.org/10.7748/ncyp.28.4.16.s20.

111. Heath G, Abdin S, Begum R, Kearney S. Putting children forward for epilepsy surgery: a qualitative study of UK parents' and health professionals' decision-making experiences. Epilepsy Behav. 2016;61:185-91. https://doi. org/10.1016/j.yebeh.2016.05.037.

112. lachini AL, Hock RM, Thomas M, Clone S. Exploring the youth and parent perspective on practitioner behaviors that promote treatment engagement. J Fam Soc Work. 2015;18(1):57-73. https://doi.org/10.1080/10522158.2014.974293.

113. Kahveci R, Ayhan D, Döner P, Cihan FG, Koç EM. Shared decision-making in pediatric intensive care units: a qualitative study with physicians, nurses and parents. Indian J Pediatr. 2014;81(12):1287-92. https://doi.org/10.1007/ s12098-014-1431-6.

114. Karnieli-Miller O, Eisikovits Z. Physician as partner or salesman? Shared decision-making in real-time encounters. Soc Sci Med. 2009;69(1):1-8. https://doi.org/10.1016/j.socscimed.2009.04.030.

115. Kavanaugh K, Savage T, Kilpatrick S, Kimura R, Hershberger P. Life support decisions for extremely premature infants: report of a pilot study. J Pediatr Nurs. 2005;20(5):347-59. https://doi.org/10.1016/.pedn.2005.03.006.

116. Lecouturier J, Clarke MP, Errington G, Hallowell N, Murtagh MJ, Thomson R. Treating childhood intermittent distance exotropia: a qualitative study of decision making. BMC Ophthalmol. 2015;15(1):112. https://doi.org/10.1186/ s12886-015-0087-y.

117. Levy SE, Frasso R, Colantonio S, et al. Shared decision making and treatment decisions for young children with autism spectrum disorder. Acad Pediatr. 2016;16(6):571-8. https://doi.org/10.1016/j.acap.2016.04.007.

118. Makworo D, Bwibo N, Omoni G. Parental involvement in the management of hospitalised children in Kenya: policy and practice. Afr J Midwifery Womens Health. 2014;8(4):183-8. https://doi.org/10.12968/ajmw.2014.8.4.183.

119. Miller VA, Nelson R, Denunzio R, et al. Parent-child collaborative decision making for the management of chronic illness: a qualitative analysis. Fam Syst Health. 2009;27(3):249-66. https://doi.org/10.1037/a0017308.

120. Pentz RD, Pelletier W, Alderfer MA, Stegenga K, Fairclough DL, Hinds PS. Shared decision-making in pediatric allogeneic blood and marrow transplantation. What if there is no decision to make? Oncologist. 2012; 17(6):881-5. https://doi.org/10.1634/theoncologist.2011-0446.

121. Ruhe KM, Wangmo T, De Clercq E, et al. Putting patient participation into practice in pediatrics-results from a qualitative study in pediatric oncology. Eur J Pediatr. 2016;175(9):1147-55. https://doi.org/10.1007/s00431-016-2754-2.

122. Sajeev M, Cohen J, Wakefield CE, Fardell JE, Cohn RJ. Decision aid for nutrition support in pediatric oncology: a pilot study. J Parenter Enter Nutr. 2017;41(8):1336-47. https://doi.org/10.1177/0148607116661840.

123. Sleath BL, Carpenter DM, Sayner R, et al. Child and caregiver involvement and shared decision-making during asthma pediatric visits. J Asthma. 2011; 48(10):1022-31. https://doi.org/10.3109/02770903.2011.626482.

124. Smith J, Cheater F, Bekker H, Chatwin J. Are parents and professionals making shared decisions about a child's care on presentation of a suspected shunt malfunction: a mixed method study? Health Expect. 2013; 18(5):1299-315. https://doi.org/10.1111/hex.12106.

125. Stille CJ, Fischer SH, La Pelle N, Dworetzky B, Mazor KM, Cooley WC. Parent partnerships in communication and decision making about subspecialty 
referrals for children with special needs. Acad Pediatr. 2013;13(2):122-32. https://doi.org/10.1016/j.acap.2012.12.003.

126. Young B, Moffett JK, Jackson D, McNulty A. Decision-making in communitybased paediatric physiotherapy: a qualitative study of children, parents and practitioners. Heal Soc Care Community. 2006;14(2):116-24. https://doi.org/ 10.1111/j.1365-2524.2006.00599.x.

127. Zwaanswijk M, Tates K, van Dulmen S, Hoogerbrugge PM, Kamps WA, Bensing JM. Young patients', parents', and survivors' communication preferences in paediatric oncology: results of online focus groups. BMC Pediatr. 2007;7(1):35. https://doi.org/10.1186/1471-2431-7-35.

Ready to submit your research? Choose BMC and benefit from:

- fast, convenient online submission

- thorough peer review by experienced researchers in your field

- rapid publication on acceptance

- support for research data, including large and complex data types

- gold Open Access which fosters wider collaboration and increased citations

- maximum visibility for your research: over $100 \mathrm{M}$ website views per year

At $\mathrm{BMC}$, research is always in progress.

Learn more biomedcentral.com/submissions 